Estudios Constitucionales, Año 11, No 1, 2013, pp. 221 - 274.

ISSN 0718-0195

Centro de Estudios Constitucionales de Chile Universidad de Talca

"El uso del derecho y jurisprudencia constitucional extranjera y de tribunales internacionales no vinculantes por el Tribunal Constitucional chileno en el período 2006-2011"

Humberto Nogueira Alcalá

\title{
EL USO DEL DERECHO Y JURISPRUDENCIA CONSTITUCIONAL EXTRANJERA Y DE TRIBUNALES INTERNACIONALES NO VINCULANTES POR EL TRIBUNAL CONSTITUCIONAL CHILENO EN EL PERÍODO 2006-2011*
}

\author{
THE USE OF CONSTITUTIONAL LAW AND FOREIGN CONSTITUTIONAL \\ JURISPRUDENCE AND NON-BINDING INTERNATIONAL COURTS BY THE \\ Chilean Constitutional Court in the Period 2006-2011
}

\author{
Humberto Nogueira Alcalá** \\ Profesor Titular de Derecho Constitucional \\ Universidad de Talca
}

RESUMEN: El presente artículo analiza la utilización del derecho extranjero y la jurisprudencia constitucional extranjera e internacional no vinculante jurídicamente para Chile en la jurisprudencia del Tribunal Constitucional chileno, durante el periodo 2006-2011, en la perspectiva del diálogo constitucional y las comunicaciones transnacionales entre jurisdicciones constitucionales de diversos paises, como, asimismo, considera si la jurisprudencia del Tribunal Constitucional utiliza la comparación jurídica asumida como "quinto método de interpretación".

ABSTRACT: This article discusses the use of foreign law and the constitutional jurisprudence foreign and international non-binding legally to Chile in the jurisprudence of the Chilean Constitutional Court, during the period 2006-2011, in the perspective of constitutional dialogue and transnational communications between constitutional jurisdictions of various countries, as it also considers whether the jurisprudence of the Constitutional Court uses the legal comparison as "fifth method of interpretation".

PaLABRAS CLAVE: Tribunales constitucionales, Derecho constitucional comparado, método comparativo, internacionalización del derecho constitucional; Sentencias extranjeras. Interpretación constitucional.

\footnotetext{
* Este artículo es parte del proyecto de investigación Fondecyt Regular No 1110016 - 2011-2013 sobre "Análisis de las sentencias del Tribunal Constitucional sobre utilización del derecho constitucional extranjero y del derecho internacional de los derechos humanos y sus implicancias para el parámetro de control de constitucionalidad" del cual el autor es investigador principal. Trabajo recibido el 10 de octubre de 2012 y aprobado el 21 de noviembre de 2012.

** Abogado. Doctor en Derecho. Profesor Titular de Derecho Constitucional, Facultad de Ciencias Jurídicas y Sociales Universidad de Talca. Miembro Asociado de la Academia Internacional de Derecho Comparado. Vicepresidente del Instituto Iberoamericano de Derecho Procesal Constitucional. Presidente de la Asociación Chilena de Derecho Constitucional. Miembro del Consejo Directivo de la Academia Judicial.nogueira@utalca.cl.
} 
KEY WORDS: Constitutional Courts, Comparative Constitutional Law, comparative methods, Internationalization of the Constitutional Law. Foreign decisions. Constitutional interpretation.

\section{INTRODUCCIÓN}

El uso del derecho constitucional y la jurisprudencia por parte de los tribunales constitucionales es un fenómeno que en los últimos años ha despertado una importante reflexión y análisis tanto dentro como fuera de las jurisdicciones constitucionales, especialmente el uso de la jurisprudencia extra sistémica o que no forma parte del respectivo sistema jurídico y su sistema de fuentes. Aun cuando avanza el estudio y el método de la comparación constitucional y su aplicación práctica, hay una resistencia significativa de paradigmas mentales que siguen considerando que el contexto local es el único que importa en la interpretación y aplicación del derecho.

Los tribunales constitucionales en la últimas décadas han comenzado a utilizar sentencias extranjeras de otros tribunales constitucionales o jurisdicciones ordinarias superiores con competencia de jurisdicción constitucional en sus razonamientos jurídicos, en la medida que han considerado que ello puede enriquecer su reflexión jurídica, sus métodos de interpretación y sus enfoques constitucionales, sin dejar de tener presente que las normas que conforman los ordenamientos jurídicos estatales están condicionadas por factores propios del lugar, la cultura y el contexto en el que están destinadas a tener aplicación y vigencia.

Tomar en cuenta las decisiones de otros tribunales constitucionales o explicar las razones por las que no se está de acuerdo con ellas, les permite encontrar enfoques de análisis y argumentos que posibilitan renovar sus paradigmas y abrirse a nuevas perspectivas no consideradas por el derecho y la jurisprudencia local. A través del análisis de las diferencias y similitudes que existen entre sistemas jurídicos o entre instituciones de dichos sistemas, la consideración de enfoques y métodos de análisis utilizados por otros tribunales extranjeros o internacionales no vinculantes para el Estado chileno, permite que puedan ser utilizados como herramientas de trabajo o, por otra parte, ellos pueden ser desechados y en ciertos casos condenados por ser contrarias a ciertos valores y principios que forman parte vertebral o esencial de un determinado sistema normativo. Finalmente, a través de la comparación puede tenerse en consideración a través de un análisis autónomo, los aciertos y errores que han desarrollado otras jurisdicciones constitucionales.

La consideración del derecho constitucional extranjero es relevante en la medida que el derecho constitucional vigente en un determinado Estado no nace 
nunca de manera aislada en la mente del constituyente o del legislador o en la actividad que desarrollan los operadores jurídicos, es evidente que muchas veces para conocer de manera adecuada un ordenamiento determinado, es necesario tomar en cuenta lo que ha sucedido más allá de las fronteras en que éste se apli$\mathrm{Ca}^{1}$, sin perjuicio de considerar las particularidades y contexto nacional en que dichas instituciones o soluciones institucionales se insertan. En la perspectiva del derecho constitucional la investigación diacrónica se cruza a menudo con la investigación y comparación sincrónica ${ }^{2}$. El uso de la comparación en derecho constitucional es relevante y posibilita, sin lugar a dudas, el comprender mejor los sistemas nacionales y su desarrollo.

\section{LOS FACTORES RELEVANTES QUE IMPULSAN LA CONSIDERACIÓN DEL DERECHO EXTRANJERO POR PARTE DE LAS JURISDICCIONES CONSTITUCIONALES}

Consideramos que los factores relevantes están dados por la doctrina que emana de los trabajos académicos que concretan análisis explicativos del fenómeno; por los abogados que invocan los enfoques metodológicos y la jurisprudencia de otros tribunales que han resuelto materias similares en sus presentaciones ante los tribunales; como, asimismo, por la jurisprudencia de otras jurisdicciones constitucionales que son leídas y reflexionadas por los magistrados que integran los órganos jurisdiccionales.

\subsection{La doctrina jurídica}

Los autores que desarrollan la doctrina y la ciencia jurídica comparativa ${ }^{3}$ y la jurisdicción constitucional comparada, observan en las sentencias de las jurisdicciones constitucionales nacionales las transferencias de normas, de principios interpretativos y de enfoques metodológicos, todos los cuales son comentados y analizados, racionalizándolos, poniendo de relieve su lógica y estructurándolos en sistema. Es a estas investigaciones a las que se acude cuando se quiere medir la realidad y la fuerza de las interacciones jurisprudenciales. Estas publicaciones muestran las corrientes de intercambio, las refuerzan, las estimulan o las critican. Es necesario admitir que la intensidad de la investigación que los académicos

\footnotetext{
${ }^{1}$ Pizzorusso (1998), p. 154.

2 ZWeigerT y KÖTZ (2008), p. 10.

3 Pegoraro, Lucio. (2001). Von Bar, C. (2004). Pegoraro, L. y Damiani, P. (1999). pp. 209-236. De Vergottini, G. (2004). Zweigert y Kötz (2008).
} 
e investigadores realizan, posibilita la socialización, la toma de conciencia y la reflexión sobre la influencia de las jurisprudencias y del diálogo o monólogo interjurisdiccional, según sea el caso.

A su vez, un correcto uso del método comparado en el derecho constitucional permite superar las aproximaciones estrictamente textualistas, con una debida consideración de los contextos de dichos ordenamientos jurídicos, enriqueciendo el aparato conceptual y argumentativo de una jurisdicción constitucional, superando la pobreza de la auto referencia, asumiendo el desafío de la posibilidad de aprender de las reflexiones jurídicas y de los aciertos como de los errores de nuestros tribunales que ejercen jurisdicción constitucional y de las jurisdicciones extranjeras.

Un primer aspecto que debe explicitarse en este ámbito es que la mera cita de sentencias de derecho constitucional extranjero no es derecho comparado, con suerte estaríamos frente a una información comparativa, que es una forma en que se concreta lo que De Vergottini determina "erudición discursiva" ${ }^{4}$, la que es útil para mostrar similitudes o diferencias de razonamientos, construcciones institucionales o modelos que permiten reforzar una argumentación o realizar un contraste, cuando ellos se realizan en materias atingentes a la ratio decidendi del caso en análisis. En otros casos, podemos decir que es sólo fuego de artificio ya que en nada contribuyen al razonamiento y argumentación de fondo sobre el caso analizado.

La mayor parte de la doctrina justifican la investigación y la consideración de precedentes extranjeros, de otros países o internacionales no vinculantes, por parte de las jurisdicciones constitucionales, en virtud del uso de argumentos similares ante hipótesis jurídicas análogas, en contextos homologables, lo que permite adoptar un razonamiento jurisprudencial como argumento de refuerzo de una decisión o como criterio básico para adoptar una resolución, en virtud de la similitud de los cuerpos normativos y de la cultura jurídica, o por el hecho de haber resuelto la misma materia otro tribunal al que se le reconoce prestigio o autoridad con anterioridad al tribunal que la considera en su sentencias.

El conocer y usar la jurisprudencia extranjera e internacional no vinculante, además de la propia, posibilita la expansión y riqueza de la argumentación constitucional, fortaleciendo la calidad argumentativa de las sentencias.

${ }^{4}$ De Vergottini (2001), p. 224.

5 Maus, (2009). p.684. 
La seriedad y prolijidad del uso del derecho extranjero e internacional no vinculante y la circulación de los precedentes jurisprudenciales requiere que exista una adecuada y correcta selección de los ordenamientos de referencia, evitando la subjetividad y la arbitrariedad de la selección de ella; que tal uso esté encaminado a una mejor comprensión del propio ordenamiento constitucional y jurídico, posibilitando una auto observación, comprensión y discernimiento crítico; como, asimismo, es necesario, explicitar los argumentos en forma honesta, haciéndolos transparentes, verificables y controlables.

La doctrina académica advierte de parte de ciertas magistraturas constitucionales, una selección puramente discrecional de las referencias y precedentes extranjeros y su utilización fuera de contexto ("cherrypicking"), el uso descontextualizado o descuidado del precedente jurisdiccional extranjero o la cita jurisprudencial desactualizada, entre otros aspectos. En esta materia debe prevalecer el uso de la prudencia por parte de las jurisdicciones, el adecuado control de ello provendrá del análisis crítico de la doctrina y de la opinión pública en materias constitucionales.

Es necesario distinguir, en esta materia, entre las referencias puntuales que realizan las sentencias a la normativa constitucional o a la jurisprudencia de tribunales extranjeros, que carece de relevancia y que constituyen sólo un elemento decorativo de la resolución jurisdiccional, la comparación soft o el uso adecuado y correcto uso del método comparativo para compartir o asumir postulados de interpretación, el desarrollo de metodología de análisis jurídico, enfoques de razonamiento, entre otros aspectos.

El uso de precedentes extranjeros por parte de un órgano jurisdiccional no se puede reducir a un transplante mecánico o automático, sin considerar los diferentes contextos jurídicos nacionales, los eventuales errores de interpretación y de utilización de las fuentes o la jurisprudencia, como, asimismo, la necesaria consideración del contexto del caso preciso que debe ser resuelto; el uso del derecho y la jurisprudencia extranjera constituyen argumentos persuasivos o para reforzar una decisión de una jurisdicción que debe siempre estar basada sobre las fuentes del derecho vigente en el derecho nacional ${ }^{6}$.

El argumento comparado y la solución jurisprudencial extranjera no es fuente del derecho ni tiene una eficacia vinculante, sólo constituye un enriquecimiento de la perspectiva hermenéutica del juez constitucional nacional, una apertura con discernimiento crítico al derecho extranjero posibilita una mejor comprensión

${ }^{6}$ De Vergottini (2010), p. 169. 
de la propia Constitución y de la propia tradición constitucional, posibilitando una mejor comprensión de instituciones comunes y valores compartidos, posibilitando abrirse a nuevas prospectivas ${ }^{7}$. Asimismo, el diálogo jurisprudencial horizontal puede ser utilizado legítimamente para reforzar las argumentaciones sostenidas en el análisis e interpretación del derecho constitucional nacional, con experiencias de derecho constitucional extranjero que cuentan con reglas y principios con la misma perspectiva cultural y constitucional y con contextos normativos similares. Todo ello debe ser asumido sin complejos de superioridad ni de inferioridad.

Como señala de Vergottini, el derecho externo (al propio ordenamiento) no debe ser tomado como fuente de aplicación en el caso en examen, "sino como dato fáctico y cognitivo que el juez tiene presente para mejor conocer y decidir" así el precedente extranjero puede ser útil y retenido tanto para determinar una compatibilidad como para determinar un desacuerdo de alcance y sentido suficientemente argumentado, como, asimismo, para estructurar soluciones jurídicas con método y estructura similar a la utilizada en el derecho comparado.

Los diálogos o monólogos jurisprudenciales sirven también para crear ideas que produzcan, además de la coexistencia pacífica y la cooperación, la integración de una pluralidad de culturas jurídicas en la unidad de una comunidad jurídica.

En el caso del diálogo jurisprudencial horizontal, el uso de la comparación y de la jurisprudencia comparada se justifica cuando ella posibilita desentrañar el significado originario de una norma que se ha incorporado al derecho constitucional local pero que es de derivación de otro ordenamiento constitucional, aunque siempre teniendo presente el contexto normativo nacional en que se integra, el que puede ser distinto del ordenamiento extranjero, ello opera en el caso de determinados principios de interpretación o instituciones jurídicas, que se han recepcionado de otros ordenamientos jurídicos.

El uso del recurso al derecho comparado o a la información comparativa, por su parte, está asociado también a la apertura en la cultura jurídica y política del país a la recepción jurídica proveniente de otros ordenamientos jurídicos, a cómo las Cortes o Tribunales Constitucionales consideran el proceso de argumentación jurídica, como, asimismo, a las eventuales resistencias ideológicas o paradigmáticas de los magistrados basados en una determinada concepción de la soberanía nacional, de "patriotismo constitucional" y el temor a la pérdida de identidad

7 JACKSON (2010) p. 117.

${ }^{8}$ De Vergottini (2010) pp. 139-140. 
nacional, elementos que han sido objeto de análisis por la doctrina: Choudhry'; De Vergottini ${ }^{10}$, Jackson ${ }^{11}$, Lollini ${ }^{12}$, Ponthoreau ${ }^{13}$, Slaugther ${ }^{14}$; Sperti ${ }^{15}$, Tushnet ${ }^{16}$, Markensis y Fedtke ${ }^{17}$, entre otros.

A su vez, el diálogo o monólogo jurisprudencial horizontal es legítimo y válido cuando se utiliza para considerar puntos de vista a través de los cuales pueden desarrollarse y discernirse propuestas interpretativas, considerarse hipótesis posibles de solución de un problema jurídico constitucional, discernir la relevancia de argumentos que no se han planteado a nivel nacional para acogerlos o desecharlos, en definitiva, para enriquecer el razonamiento jurídico propio y eventualmente para superar lagunas o vacíos en el ordenamiento domestico, siempre verificando prudentemente el contexto normativo nacional y la armonización de la solución hermenéutica con la perspectiva constitucional positiva nacional.

\subsection{La jurisprudencia}

Es por la jurisprudencia que se ejerce la influencia recíproca de las jurisdicciones. La literatura acerca de la jurisprudencia y líneas jurisprudenciales de los tribunales es el primer modo de comunicación entre los jueces. Son las resoluciones que ellos adoptan las que son consideradas por los otros jueces. La autoridad de la jurisprudencia puede ser obligatoria o consentida, según sea el vínculo jurídico que une a los tribunales o cortes en relación.

La autoridad de la jurisprudencia de un tribunal o corte es diferente, según la relevancia de la respectiva jurisdicción, su calidad argumental, su autoridad moral, la fuerza de convicción de su motivación, la calidad del sistema jurídico del cual emana el juzgamiento. En este ámbito, cada jurisdicción internacional y nacional se encuentra en competencia con las demás.

\footnotetext{
9 Choudry, S. (2006).

${ }^{10}$ De Vergottini (2010).

${ }^{11}$ JACKSON (2010).

${ }^{12}$ LolLini (2009), pp. 165-182.

13 Ponthoreau (2005), pp. 145 y ss.

14 Slaugther, (1994), pp. 99-137.

15 Sperti, (2006), pp. 125-165.

16 Tushnet (1999), pp. 1225 y ss.

17 Markensis y FedtKe (2009).
} 
Es por el modo de decisión reflexiva de los jueces de sus sentencias y la calidad de su análisis, que se propagan los modelos de justicia y se desarrollan las interacciones entre jurisprudencias internas, como, asimismo, con otras extranjeras de diversos estados parte de un mismo sistema jurídico o de distintos sistemas jurídicos.

La recepción de jurisprudencias puede no reposar en ningún principio jurídico, siendo una práctica corriente, cuando se invocan, por ejemplo, en el caso de nuestro Tribunal constitucional, diversas referencias a la jurisprudencia del Tribunal Europeo de Derechos Humanos, o cuando considera otras resoluciones de otras cortes o jurisdicciones constitucionales, no encontrándose obligados a realizar dicha comunicación interjurisdiccional.

Tratándose de jueces constitucionales las corrientes de interrelación se refuerzan por la creación de organizaciones internacionales que los reúnen y en las cuales se analizan temas específicos y jurisprudencias, además de analizar problemas comunes, como ocurre, por ejemplo, en las reuniones anuales de jurisdicciones constitucionales latinoamericanas con el patrocinio de la Fondación Konrad Adenauer, a las cuales se ha integrado la Corte Interamericana de Derechos Humanos; los seminarios y encuentros de la Asociación de Tribunales Constitucionales Europeos; las reuniones de la Asociación de Cortes Constitucionales que participan del uso del idioma francés (ACCPUF); las reuniones de la Comisión de Venecia, como, asimismo, la importante base de datos de esta sobre jurisprudencia constitucional (CODICES) de los tribunales constitucionales participantes en ella.

Las comunicaciones jurisdiccionales horizontales que se concretan entre jurisdicciones constitucionales o entre estas y Cortes Supremas de diversos estados son voluntarias y espontáneas, no existe ningún argumento normativo para ello, sólo se concreta en virtud de lo que los propios magistrados consideran relevante y útil considerar para resolver la controversia que está en sus manos, materia ya analizada por Markenzis y Fedtke ${ }^{18}$, donde determinados tribunales constitucionales utilizan la ratio decidendi de las sentencias de otros tribunales constitucionales u ordinarios los que constituyen instrumentos útiles que permiten reflexionar con mayor profundidad sobre un problema jurídico, obtener criterios adecuados para resolver un problema constitucional, tener presente aristas no consideradas, ampliar perspectivas, y enriquecer las argumentaciones jurídicas para resolver los problemas jurídicos constitucionales nacionales que

${ }^{18}$ Markensis, B. y Fedtke, J. (2009). 
son parte de su competencia, los que se incorporan en el cuerpo de la sentencia propiamente tal o en votos concurrentes o disidentes.

El uso del argumento de derecho comparado, información comparativa o "comparación interestatal" ${ }^{19}$, según sea el caso, tiene especialmente sentido cuando el análisis de los ordenamientos o de la jurisprudencia extranjera posibilitan al intérprete paradigmas de razonamiento jurídico que no están presentes en la lectura interna o local del problema sujeto a análisis; asimismo, el uso del derecho extranjero es útil para verificar una cierta solución funcional en la práctica, posibilitando al tribunal o corte formular un argumento empírico acerca de la consecuencia de una determinada solución al caso específico.

Debe tenerse presente que el uso de la jurisprudencia extranjera no genera necesariamente una interacción o diálogo entre jurisdicciones o tribunales, sino que puede constituir un monólogo, en el que determinados tribunales citan jurisprudencia de otros sin que ello genere ninguna interrelación entre ambos tribunales. En tales casos, los jueces de un determinado tribunal confrontan la jurisprudencia de otros tribunales y los argumentos y doctrinas utilizados en ellas con los parámetros, razonamientos y precedentes nacionales, como elementos a considerar en la construcción de la solución al caso concreto, lo que le permite tener conciencia crítica de sus propios argumentos y fuentes del derecho, frente a otras perspectivas similares o diversas existentes en el derecho comparado.

\subsection{La actividad de los abogados ante los tribunales}

Al lado de los jueces, los abogados son importantes vectores de influencia. Son ellos quienes por las referencias que invocan y las citaciones que realizan de doctrinas y jurisprudencias externas en estrados, establecen concordancias entre las resoluciones jurisdiccionales de cortes internacionales y extranjeras con el derecho interno. Los abogados al aludir en sus escritos y alegatos a principios interpretativos desarrollados por la doctrina o algunos tribunales extranjeros o internacionales, al realizar citas pertinentes de precedentes jurisdiccionales, al considerar adecuadamente enfoques comparativos, obligan a las jurisdicciones constitucionales a considerar y argumentar fundadamente sobre tales consideraciones, que de no ser invocadas no habrían sido consideradas en el razonamiento ni en la resolución judicial.

19 Ver CAROZZa (1998). pp. 1218-1219. 


\section{Consideraciones SObRe la UTILIZACión DEL DERECHO NO DOMÉSTICO} por el Tribunal Constitucional Chileno en el Periodo 2006-2011

En el análisis efectuado de las resoluciones de nuestro Tribunal Constitucional en el periodo objeto de investigación, se consideran las alusiones al derecho constitucional extranjero tanto de carácter normativo y jurisprudencial, como las referencias a normas internacionales y la jurisprudencia de tribunales internacionales no vinculantes para el Estado chileno; considerándose el análisis de las citaciones en si msmas y las jurisdicciones de las cuales ellas emanan; las materias en las que se concretan las alusiones al derecho extranjero e internacional no vinculante; el tipo de tribunales citados; la modalidad de citas desarrolladas y su utilización en la ratio decidendi o como obiter dicta de la sentencia constitucional chilena.

\subsection{Análisis cuantitativo de sentencias que utilizan derecho extranjero o} internacional no vinculante para el Estado de Chile en el período 2006-2011 y determinación de jurisdicciones citadas

En el ámbito de la jurisdicción constitucional chilena, en general, hasta el año 2006, hay un uso del derecho constitucional formalista descriptivo y eminentemente positivista que utiliza poco el recurso al derecho constitucional comparado, la información comparativa y la jurisprudencia comparada; dicha tendencia se quiebra el año 2007, donde hay una apertura al derecho internacional de los derechos humanos y al uso del derecho constitucional y la jurisprudencia de otros tribunales constitucionales, lo que se mantiene con posterioridad a dicha fecha, aunque con altibajos.

En el año 2006, ya se encuentran alusiones al derecho constitucional comparado, pero solamente en votos concurrentes o disidentes.

En sentencia, Rol No 480 de 27 de julio de 2006, en voto concurrente de los ministros Marcelo Venegas Palacios y Enrique Navarro Beltrán, estos establecen para reforzar su argumentación jurídica, el uso de jurisprudencia del Tribunal Constitucional Español, en materia de predeterminación normativa de las conductas y de las sanciones en el ámbito penal y administrativo sancionatorio; a su vez, el Ministro Jorge Correa Sutil, se refiere al uso del derecho comparado europeo, para explicitar las diferencias de enfoque en dicho contexto, como, asimismo, para establecer la diferencias entre el texto constitucional chileno y español sobre el derecho administrativo sancionador. 
En sentencia Rol No 546 de diecisiete de noviembre de dos mil seis, en que no hay decisión por empate de votos, los cinco ministros que rechazan el requerimiento que cuestiona el Solve y Repete analizan el uso de dicha institución por diversos ordenamientos jurídicos europeos y por algunas jurisdicciones como las de Italia, España, Colombia y Argentina, como, asimismo, se refieren a la Declaración Universal de Derechos Humanos. En el considerando undécimo de la sentencia el Tribunal Constitucional recurre a la información comparativa en los siguientes términos:

"Que dichos reparos de juridicidad también los ha señalado la jurisprudencia emanada de diversos tribunales tanto en Europa como en América. Asi lo precisó la Corte Constitucional italiana en fallo de 31 de marzo de 1961. En España, a su vez, lo señaló la judicatura en sendas resoluciones de 26 de noviembre de 1985 y 17 de enero de 1969. Sin embargo el Tribunal Constitucional español en diversos fallos también ha aceptado la consignación en materia laboral respetando el principio de razonabilidad y proporcionalidad con las finalidades de asegurar la debida ejecución de la sentencia, evitar la presentación de recursos meramente dilatorios y a su vez afectar la irrenunciabilidad de los derechos del trabajador (véase, al efecto, sentencias de 28 de febrero y 14 de marzo, ambas de 1983). A su turno, en materia tributaria es aceptado en ciertas legislaciones, como es el caso de Argentina (Roberto Dromi, Instituciones de Derecho Administrativo, p. 256) y Estados Unidos (bajo la fórmula 'pay first, litigate later' o full payment rule'). A su turno en Colombia, la Corte Suprema, en sentencia de 12 de marzo de 1987, consigna que 'el trámite previo exigido por la norma para que el particular acceda a los recursos (...) es decir, la consignación de la multa impuesta, es en sí mismo inconstitucional, por cuanto coloca al ciudadano en la imposibilidad de ejercer su defensa ante el Estado, si carece de dinero necesario para efectuar la consignación. Como puede apreciarse existen criterios disimiles, lo que supone prudencia legislativa aunque cierto es enfatizar que en algunos casos existe justicia contenciosa administrativa especializada"'.

El año 2007, puede constatarse que el Tribunal Constitucional, en sus sentencias en acciones de inaplicabilidad por inconstitucionalidad, tiene una perspectiva de mayor consideración del derecho constitucional y la jurisprudencia de tribunales constitucionales extranjeros, como elementos de análisis que le permiten una mayor riqueza de análisis para resolver los casos concretos.

En tres sentencias el Tribunal utiliza normas de derecho constitucional extranjero de Estados Unidos, Alemania, España, Francia e Italia (Roles $\mathrm{No}^{\circ} .718$, 759 y 773). Una sentencia se refiere a concepciones sobre justicia administrativa en el derecho positivo de diversos estados en referencia abstracta y sin precisión, lo que le permite sostener la existencia de diversos modelos de justicia administrativa, posibilitando algunas clasificaciones de ellos, determinando la 
existencia de opciones similares a la chilena, lo que le permite considerar como legítimo el modelo nacional sobre la materia (Rol No 616). Respecto de las citas de jurisprudencia de otros tribunales constitucionales, puede establecerse que doce sentencias citan jurisprudencia del Tribunal Constitucional español (Roles Nos. 519, 527, 549, 576, 616, 664, 718, 759, 773, 783, 786, 790); en tres sentencian cita jurisprudencia de la Corte Constitucional alemana (Roles $\mathrm{No}_{\text {s. }} 616$, 786, 790); en tres sentencias se cita jurisprudencia del Consejo Constitucional francés (Roles $\mathrm{No}_{\text {s. }}$ 616, 664 y 786); en dos sentencias hay referencias a la jurisprudencia del Tribunal Constitucional de Italia (Roles $\mathrm{No}^{\text {s. }} 616$ y 786); en dos sentencias hay citas de jurisprudencia del Tribunal Constitucional de Perú (Roles Nos. 718 y 786); en dos sentencias se cita jurisprudencia de la Corte Suprema de México (Roles Nos. 718 y 780), y en dos sentencias hay citas de fallos de la Corte Constitucional de Colombia (Roles Nos. 790 y 804).

Asimismo, en una sentencia se hace referencia genérica al derecho de Francia, Inglaterra, Alemania, España, Estados Unidos y al derecho hispanoamericano con referencias a diversos países considerando la diversidad de sistemas de justicia administrativa (Rol No 616).

En una sentencia se utilizan las reglas de la Convención de Viena sobre Derecho de los Tratados (Rol No 804).

En el año 2008, el Tribunal Constitucional se refirió en nueve sentencias a fallos del Tribunal Constitucional español (Roles Nos. 986, 755, 821, 968, $1170,1216,1133$ y 1056); en más de veinte sentencias se alude a un fallo del Tribunal Constitucional de Austria en obiter dicta que ilustra sobre la posibilidad de éste de dictar sentencias con efecto retroactivo (entre otros, Roles $\mathrm{No}_{s} .964$ a 974, 880, 878 y 978); en cinco sentencias se acude a jurisprudencia de la Corte Constitucional Alemana (Roles Nos. 986, 821, 1170, 1133 y 1065); en cinco sentencias se considera jurisprudencia del Consejo Constitucional Francés (en Roles Nos. 986, 821, 740, 1216 y 1065); en cuatro sentencias se utilizan fallos del Tribunal Constitucional italiano (Roles $\mathrm{No}^{\circ}$. 986, 821, 968 y 1065); en tres sentencias se alude a resoluciones de la Corte Constitucional de Colombia; en tres sentencias se citan fallos de la Sala Constitucional de Costa Rica (Roles Nos. 755, 740 y 1138); en un caso, se consideran sentencias de la Corte Suprema Argentina (Rol No 740); en otro caso, en voto disidente, se considera un fallo de la Corte Suprema Norteamericana (Rol No 740).

En el año 2009, el Tribunal Constitucional se refirió en nueve sentencias a fallos del Tribunal Constitucional Español (Roles Nos. 1140, 1204, 1247, $1250,1361,1345,1254,1340,1295)$; en dos sentencias a resoluciones de la 
Corte Constitucional de Alemania (Roles Noos. 1140, 1295); en dos sentencias se alude a fallos del Consejo Constitucional Francés (Roles Nos. 1361 y 1295); en una sentencia a precedentes jurisprudenciales del Tribunal Constitucional italiano (Rol No 1345); en tres sentencias se invocan fallos de la Sala Constitucional de la Corte Suprema de Costa Rica (Roles Nos. 1140, 1254, 1340); en dos sentencias se consideran fallos de la Corte Constitucional de Colombia (Roles $\mathrm{No}_{\text {s. }} 1140$ y 1254); en dos sentencias se invoca jurisprudencia de la Corte Europea de Derechos Humanos (Roles Nos. 1140 y 1254) y en una sentencia se invoca jurisprudencia de la Corte Suprema de los Estados Unidos de América (Rol No 1295).

A su vez, el Tribunal Constitucional utiliza citas de la Constitución Española en dos sentencias (Roles Nos. 1254 y 1288), y una cita de la Constitución Alemana (Rol No 1288).

En el año 2010, el Tribunal Constitucional se refirió en siete sentencias al Tribunal Constitucional Español (Roles Nos. 1535, 1365, 1348, 1414, 1710, 1399-09 y 1469-09, y 1413-09); en cinco sentencias se alude a fallos de la Corte Constitucional de Alemania (Roles Nos. 1365, 1273, 1348, 1414, y 1710; 1399-09 y 1469-09); en una sentencia a fallos de la Corte Suprema Argentina (Rol No 1588); en una sentencia se considera fallo del Tribunal Constitucional del Ecuador (Rol No 1588), en una sentencia se cita jurisprudencia del Tribunal Constitucional del Perú (Rol No 1588), y en dos sentencias se alude a fallos del Tribunal Europeo de Derechos Humanos (Roles Nos. 1365 y No 567).

El Tribunal Constitucional realiza en sus fallos referencias a las constituciones de España (Roles Nos. 1588, 567 y 1416-09); de Alemania (Roles Nos. 157609 y 1416-09); de Italia (Rol No 1576-09); de Argentina (Rol No 1576-09); de Colombia (Rol No 1576-09); de Perú (Rol No 1576-09), y de México (Rol No 1576-09).

En el año 2011 disminuye significativamente el número de sentencias que utilizan normas constitucionales y jurisprudencia constitucional extranjera y del Tribunal Europeo de Derechos Humanos, sólo cuatro sentencias (Roles No 168310, No 1537-09 No 1656-10, y No 1881-10); sin embargo, ellas mantienen la tendencia general de las citas a jurisdicciones constitucionales europeas, algunas jurisdicciones latinoamericanas y a ordenamientos constitucionales europeos y latinoamericanos, como, asimismo, al Tribunal Europeo de Derechos Humanos, tanto en las sentencias como en los votos concurrentes y disidentes.

En efecto, el Tribunal Constitucional se refirió en tres sentencias a fallos del Tribunal Constitucional Español (Roles No 1683-10, No 1537-09 y No 1656- 
10); en dos sentencias alude a jurisprudencia de la Corte Constitucional Colombiana (Roles No 1683-10, No 1537-09 y No 1656-10); en una sentencia se consideran fallos de la Corte Constitucional de Alemania (Rol No 1881-10); en una sentencia se cita jurisprudencia de la Corte Constitucional Alemana (Rol No 1881-10); en una sentencia se utiliza un fallo del Tribunal Constitucional de Austria (Rol No 1683-10); en una sentencia se alude a jurisprudencia de la Corte Sudafricana (Rol No 1683-10); en una sentencia se utiliza resoluciones de la Corte Suprema de Estados Unidos de Norteamérica (Rol No 1683), y en dos sentencias se alude a fallos del Tribunal Europeo de Derechos Humanos (Roles No 1683 y No 1881-10).

A su vez, la sentencia Rol No 1683-10 utiliza disposiciones constitucionales precisas de la Constitución Alemana, Española y de Brasil; por su parte, la sentencia Rol No 1881-10, hace referencias genéricas a las constituciones de Alemania, Bolivia, Brasil, Colombia, Ecuador, Paraguay y Venezuela.

Es posible señalar a partir del análisis jurisprudencial cuantitativo efectuado en el periodo, que nuestro Tribunal Constitucional cita preferentemente jurisdicciones constitucionales europeas con las cuales tiene mayor contacto, como ocurre con la Corte Constitucional Alemana, el Consejo Constitucional francés y los tribunales constitucionales Español e Italiano, especialmente; como asimismo algunas jurisdicciones constitucionales que corresponden a la misma cultura jurídica y ámbito regional geográfico latinoamericano, como son la Corte Constitucional de Colombia, el Tribunal Constitucional de Perú y Corte Suprema de México, el Tribunal Supremo Federal de Brasil, la Corte Suprema Argentina y la Sala Constitucional de la Corte Suprema de Costa Rica.

Ello implica reconocer que los tribunales mayormente citados son de derecho continental y no de "common law", las citas de jurisprudencia norteamericana son muy escasas, como, asimismo, la jurisprudencia sudafricana; las alusiones a las jurisdicciones canadiense o británica es inexistente.

En el análisis de falllos del Tribunal Constitucional, en el periodo considerado, es posible señalar que es posible constatar un mayor énfasis en la consideración de sentencias de jurisdicciones constitucionales europeas, donde ocupa un primer lugar indiscutido el Tribunal Constitucional español, lo que se entiende adicionalmente por compartir la misma lengua, luego vienen las citas de los tribunales de Alemania, Italia, Francia y Austria. En una segunda línea quedan las citas de jurisdicciones constitucionales de América Latina, donde se alude a sentencias de la Corte Constitucional Colombiana, la Sala Constitucional de la Corte Suprema de Costa Rica, el Tribunal Constitucional Peruano y la Corte Suprema argenti- 
na y con menor mención la Corte Suprema de México y el Tribunal Supremo Federal de Brasil.

Las citas jurisprudenciales del Tribunal Constitucional chileno se refieren a tribunales que ejercen competencia en jurisdicción constitucional con independencia de si ellos son efectivamente tribunales constitucionales extra poder (Cortes y Tribunales Constitucionales de Alemania, Austria, Colombia, España, Francia, Italia, Perú) o por órganos jurisdiccionales constitucionales dentro del poder o rama judicial (la Corte Constitucional de Alemania y Colombia, la Sala Constitucional de la Corte Suprema de Costa Rica); o tribunales supremos ordinarios con competencias de jurisdicción constitucional (la Corte Suprema argentina; el Tribunal Supremo Federal de Brasil, la Corte Suprema de los Estados Unidos de América, y la Suprema Corte Federal de México).

\subsection{Las materias que son objeto de citas de derecho o jurisprudencia constitucional extranjera o de tribunales internacionales no vinculantes en el periodo analizado}

Las materias que son objeto de consideración por nuestro Tribunal Constitucional en la jurisprudencia constitucional extranjera se vinculan con el derecho a la vida del nasciturus (Rol No 740 de 2008); derecho a la igualdad ante la ley, igualdades esenciales, justificación razonable y objetiva de las diferencias y aplicación del principio de proporcionalidad (Roles No 784 de 2007, No 986, No 1170 y No 1133 de 2008, No 1217, No 1204 , No 1340 de 2009, Nos. 1348, 1365, 1367, 1399, 1414, 1419, 1535, 1576 y 1710 de 2010 y Nos. 1656 y 1881 de 2011); el derecho a la jurisdicción y debido proceso (Rol No 1588 de 2010); consideración del solve y repete (Roles No 968 de de 2008 y No 1345 de 25 de 2009); la reformatio in pejus ( Rol No 1250 de 2009); el principio de legalidad del derecho sancionador (Roles $\mathrm{No}^{\circ}$ s. 480 de 2006 y 549 de 2007); la delimitación del derecho a la protección de la vida privada, intimidad y libre desarrollo de la personalidad (Rol No 1419-09 de nueve de noviembre de 2010); los registros de ADN en materia penal (Rol No 1365 de 8 de abril de 2010); el derecho al libre desarrollo de la personalidad, la homosexualidad, la sodomía y protección de menores de edad (Roles No 1683 y No 1683-10 de 2011); el derecho a la identidad y reconocimiento de paternidad (Roles Nos. 1416-09, 1656-10 y 1537-10 de 2011); la afectación del derecho a la honra e indemnización del daño provocado (Rol No 1416-09 de 2010); la libertad de conciencia e ideológica (Rol No 567 de 2010); la libertad de expresión e información y derecho de aclaración o rectificación (Rol No 1247 de 2009); la autonomía 
universitaria (Rol No 523 de 2007); prisión por deudas (Rol No 616 de 2007); el derecho de asociación y regulación penal (Roles Nos. 1348 y 567 de 2010); movimientos políticos y límites a la tolerancia ideológica y política (Rol No 567 2006 de 2 de junio de 2010); la justicia administrativa y derecho administrativo sancionador (Rol No 616 de 2007); la concepción de familia y regímenes matrimoniales (Rol No 1881-10 de 2011); la regulaciones de tributos y cargas públicas (Roles No 718, No 733 y No 759 de 2007); la carga de abogado de turno y su remuneración (Roles No 755, No 1138 de 2008, Roles No 1140 y No 1254 de 2009); la expropiación (Rol No 1576-09 de 2010); los requisitos de medidas restrictivas de derechos fundamentales (Rol No 1365 de 2010); control de constitucionalidad de tratados internacionales (Roles No 1254 y No 1288 de 2009); control de constitucionalidad de reglamentos parlamentarios (Rol No 1216 de 2008); la modalidad de control concreto de constitucionalidad (Rol No 1029 de 2008); límites de la jurisdicción constitucional en el mérito de los preceptos legales (Roles Nos. 554 de 2007, 1029 de 2008, 1140, 1361, 1295 y 1361 de 2009).

\subsection{El tipo de citas realizadas por el Tribunal Constitucional de la jurisprudencia y del derecho constitucional extranjero}

El Tribunal Constitucional cuando alude en sus sentencias a la jurisprudencia de otros tribunales nacionales e internacionales en oportunidades realiza citas precisas y concisas, en otras oportunidades realiza citas genéricas que impiden tener una referencia adecuada que posibilite comprobar el aserto señalado en la afirmación realizada; finalmente, hay citas indirectas a la jurisprudencia de tribunales constitucionales extranjeros o jurisdicciones internacionales no vinculantes para Chile.

\subsubsection{Las citas precisas y concisas del derecho o la jurisprudencia constitucional extranjera}

En la perspectiva de citas precisas y concisas pueden señalarse algunos fallos como algunos ejemplos:

La sentencia 986 del 30 de enero de 2008 , en su considerando $32^{\circ}$, el cual en el tratamiento del principio y derecho de igualdad ante la ley, establece diversas citas a la jurisprudencia del Tribunal Constitucional español: respecto de la garantía jurídica de la igualdad: 
"(...) supone, entonces, la diferenciación razonable entre quienes no se encuentren en la misma condición; pues no se impide que la legislación contemple en forma distinta situaciones diferentes, siempre que la discriminación no sea arbitraria ni responda a un propósito de hostilidad contra determinada persona o grupo de personas, o importe indebido, favor o privilegio personal o de grupo, debiendo quedar suficientemente claro que el legislador, en ejercicio de sus potestades, puede establecer regimenes especiales, diferenciados y desiguales, siempre que ello no revista el carácter de arbitrario". Cabe agregar que, dentro de dicha tendencia, en materia de derecho comparado, se ha declarado que "no toda desigualdad de trato resulta contraria al principio de igualdad, sino aquella que se funda en una diferencia de supuestos de hecho injustificados de acuerdo con criterios o juicios de valor generalmente aceptados" (Tribunal Constitucional español, sentencia 128/1987 de 16 de julio de 1987). Cabe agregar que, dentro de dicha tendencia, en materia de derecho comparado, se ha declarado que "no toda desigualdad de trato resulta contraria al principio de igualdad, sino aquella que se funda en una diferencia de supuestos de hecho injustificados de acuerdo con criterios o juicios de valor generalmente aceptados" (Tribunal Constitucional español, sentencia 128/1987 de 16 de julio de 1987) y que "la igualdad ante la ley consiste en que cuando los supuestos de hecho sean iguales, las consecuencias juridicas que se extraigan de tales supuestos de hecho han de ser asimismo iguales. $Y$ que deben considerarse iguales los supuestos de hecho cuando la introducción en uno de ellos de un elemento o factor que permita diferenciarlo del otro, haya de considerarse falta de un fundamento racional y -sea por ende arbitraria-por no ser tal factor diferencial necesario para la protección de bienes y derechos, buscada por el legislador" (Tribunal Constitucional español, sentencia 103/1983, de 22 de noviembre de 1983.

En la sentencia Rol No 755 de 31 de marzo de 2008, en su considerando en el considerando $40^{\circ}$, reitera la jurisprudencia del Rol No 790, sin perjuicio de señalar que ella se encuentra afirmada por el Tribunal Constitucional español en sus sentencias 76/1990 y 253/2004:

"para que la diferenciación resulte constitucionalmente lícita no basta que lo sea el fin que con ella se persigue, sino que es indispensable además que las consecuencias jurídicas que resultan de tal distorsión sean adecuadas y proporcionadas a dicho fin, de manera que la relación entre la medida adoptada, el resultado que produce y el fin pretendido por el legislador supere un juicio de proporcionalidad en sede constitucional, evitando resultados especialmente gravosos o desmedidos".

En la misma sentencia Rol No 755 de marzo de 2008, se utiliza la jurisprudencia de la Sala Cuarta de la Corte Suprema de Costa Rica en la que se sostiene la misma posición del Tribunal Constitucional chileno, en que ha precisado que si bien resulta ajustada la circunstancia de que se designe un defensor de oficio, 
"lo que si estima esta Sala contrario a la Constitución Política es la obligatoriedad que impone el artículo 159 de la Ley Orgánica del Poder Judicial de asumir esas defensas de oficio gratuitamente, pues si ese mismo órgano estatal cuenta con un cuerpo de defensores públicos pagados a cargo de su presupuesto, resulta contrario a los artículos 33 y 57 constitucionales que los defensores de oficio tengan que colaborar con el Estado en el cumplimiento de una de sus obligaciones para con los habitantes del pais, sin tener a cambio remuneración alguna, mientras que otros profesionales que cumplen igual función sí reciben la respectiva paga por iguales servicios" (Res. 06420-98).

En sentencia Rol No 740 de 18 de abril de 2008, el Tribunal Constitucional al resolver sobre la constitucionalidad de normas administrativas que permiten la distribución de "Postinor 2" a mujeres con el objeto de anticoncepción y evitar embarazos, el tribunal considera la jurisprudencia del Tribunal Constitucional de Ecuador de mayo de 2006:

"A su vez, en sentencia de amparo constitucional, dictada el 23 de mayo de 2006, por la Tercera Sala del Tribunal Constitucional del Ecuador, dirigida a obtener la suspensión definitiva del otorgamiento del registro sanitario para la comercialización y expendio de la "pastilla del día siguiente, conocida con el nombre de 'Postinor 2', se dejó constancia de que: "(..) esta Sala, consciente de todo el debate cientifico y social, no puede aseverar que la concepción se produce desde la fecundación del óvulo, pero tampoco puede estar seguro (sic) de lo contrario" (considerando 10 ${ }^{\circ}$.

Asimismo, en apoyo a la perspectiva que asume el Tribunal Constitucional de protección de la vida desde la concepción cita la jurisprudencia de la Sala Constitucional de la Corte Suprema de Costa Rica de marzo de 2000 y fallo de la Corte Suprema Argentina de 5 de marzo de 2002, en su considerando 51:

"Que la jurisprudencia de otros tribunales del continente se ha expresado en términos similares a los que se han venido explicando. Asi, la Corte Suprema de Costa Rica, en sentencia de 15 de marzo de 2000, sostuvo que 'en cuanto ha sido concebida, una persona es una persona y estamos ante un ser vivo, con derecho a ser protegido por el ordenamiento jurídico' (citada en el Informe en Derecho de los Profesores Alejandro Silva Bascuñán y Francisco Cumplido Cereceda acompañado por la Fundación de Estudios Evangélicos). Por su parte, la Corte Suprema de Justicia de la Nación argentina, en fallo de 5 de marzo de 2002, en los autos sobre amparo incoados por la entidad Portal de Belén, ha señalado que:

'En la causa T.,S.', antes citada, este Tribunal ha reafirmado el pleno derecho a la vida desde la concepción (voto de la mayoría, considerandos 11 y 12 y disidencia de los jueces Nazareno y Boggiano). También ha dicho que el hombre es eje y centro de todo el sistema jurídico y en tanto fin en si mismo - más allá de su naturaleza trascendente- su perso- 
EL USO DEL DERECHO Y JURISPRUDENCIA CONSTITUCIONAL EXTRANJERA Y DE TRIBUNALES INTERNACIONALES

na es inviolable y constituye un valor fundamental con respecto al cual los restantes valores tienen siempre carácter instrumental (Fallos: 316:479, votos concurrentes) (considerando 120)".

Dichas consideraciones jurídicas le permiten afirmar al Tribunal Constitucional como parte de su "ratio decidendi", en el considerando $67^{\circ}$ :

"la duda razonable suscitada en estos sentenciadores acerca de si la distribución obligatoria de la 'pildora del día después' en los establecimientos que integran la Red Asistencial del Sistema Nacional de Servicios de Salud puede ocasionar la interrupción de la vida del embrión, al impedirle implantarse en el endometrio femenino, genera, a su vez, una incertidumbre acerca de una posible afectación del derecho a la vida de quien ya es persona desde su concepción en los términos asegurados por el artículo $19 N^{o} 1$ de la Constitución. La referida duda debe llevar, de acuerdo a lo que se ha razonado, a privilegiar aquella interpretación que favorezca el derecho de 'la persona' a la vida frente a cualquiera otra interpretación que suponga anular ese derecho".

En la sentencia Rol No 968 de 10 de julio de 2008, el Tribunal Constitucional analiza la eventual inaplicabilidad por inconstitucionalidad de la institución del "Solve y Repete". En tal análisis tiene en consideración en el considerando 22", la jurisprudencia constitucional de la Corte Constitucional italiana, en su sentencia de 24 de marzo de 1961, en la que declaró la ilegitimidad constitucional de una norma contenida en la ley de 20 de marzo de 1865 , por estimar que el principio solve et repete infringía los artículos 30, 24 y 113 de la Constitución italiana. Las aludidas normas constitucionales consagran, respectivamente, la igualdad ante la ley (artículo 3o), el libre acceso a la justicia y el derecho a la defensa jurídica (artículo 24) y el derecho a recurrir de los actos de la Administración (artículo 113). El Tribunal Constitucional chileno transcribe algunos de los considerandos relevantes traducidos de la sentencia del Tribunal Constitucional italiano:

"El solve et repete es, sin duda, una medida particularmente enérgica y eficaz para realizar el interés público relativo a la percepción de impuestos y, precisamente por esta razón, fue introducido y se ha conservado durante tanto tiempo en la legislación italiana, a pesar de los diferentes proyectos para su supresión, de iniciativa gubernamental y parlamentaria, y a pesar de haber sido sometido durante gran tiempo a severas criticas por la doctrina y a interpretaciones correctivas y restrictivas por la jurisprudencia, la cual, a su vez, ha excluido la aplicabilidad del mismo instituto cuando la pretensión tributaria resulta, a prima facie, absolutamente infundada.

Todo esto confirma que, incluso independientemente de los principios contenidos en la Constitución, y ya antes de su aprobación, se aprecia una importante evolución en la sensibilidad del medio jurídico, la que debe ser correspondida con la interpretación y 
aplicación de las normas vigentes: evolución causada precisamente por la excesividad de esa medida, que parece no consentida por los principios informadores de un ordenamiento moderno en cuanto a las relaciones entre el ciudadano y el Estado.

El Tribunal, por lo tanto, es de la opinión que el instituto del solve et repete es contrario a las normas de la Constitución y que debe ser declarada ilegitima la disposición que lo establezca".

A su vez, en el considerando $23^{\circ}$ del fallo se considera la sentencia del Tribunal Supremo de España, (STS 3 de enero de 1985 y 25 de noviembre de 1986), a través de su Sala de lo contencioso, la cual marcó una clara evolución hacia el rechazo del privilegio del solve et repete. En efecto, se analiza la STS 6743/2000 de 25 de septiembre de 2000, en la cual la misma Sala se encarga de ilustrar la evolución de su posición en esta materia al señalar:

“(...) CUARTO.- La jurisprudencia de esta Sala ha tenido ya ocasión de pronunciarse en múltiples ocasiones sobre la regla que hace de la consignación, aval o, claro está, del pago de la cantidad reclamada por la Administración una carga previa para poder recurrir. Hasta el punto de que puede hablarse de una clara evolución, en la que tal privilegio de la Administración se ha contemplado desde su eventual incompatibilidad con los principios y derechos de igualdad y no discriminación, en perjuicio de los económicamente débiles, y de tutela judicial efectiva, especialmente después de la Constitución; así como desde la exigencia del necesario rango normativo para su eventual imposición. (...) En consecuencia, es, en la actualidad, doctrina de esta Sala:

a) La regla 'solve et repete', con independencia del rango normativo en que se establezca, puede resultar contraria a la Constitución si su formulación en términos absolutos-concebida sin excepciones en función de la auténtica posibilidad económica de asumir la carga del previo pago, de la previa consignación o de la garantía requerida-, se traduce en un obstáculo efectivo para el acceso a los Tribunales (Cfr. AATS 31 de mayo de 1996 y 21 de marzo de 1997 y SSTS 2 de julio de 1997 y 16 de diciembre de 1999).

(...) Por consiguiente, para la exigencia del previo pago, consignación o garantía determinada para la admisibilidad de los recursos, tanto administrativos como judiciales, en los términos en que lo permiten los reiterados derechos y principios constitucionales, hace falta que asi se establezca en ley formal (SSTS 29 de diciembre de 1986, 20 de enero de 1987). En esta dirección abundan también las siguientes razones: 10) la coordinación del ámbito del principio en vía administrativa y jurisdiccional, pues carecería de sentido la admisión indiscriminada del previo pago en los recursos administrativos que eludiría la fiscalización jurisdiccional por el simple hecho de que las normas reglamentarias obligaran a ello; 2o) la necesidad de una interpretación restrictiva del principio solve et repete', al carecer de fundamento cientifico y constituir un privilegio de la Administración exorbitante al tener siempre en sus manos, como luego se dirá, la ejecutividad del acto administrativo, salvo en los casos en que se acuerde su suspensión, y 30) por la 
EL USO DEL DERECHO Y JURISPRUDENCIA CONSTITUCIONAL EXTRANJERA Y DE TRIBUNALES INTERNACIONALES

discriminación, en perjuicio de los económicamente débiles, y subsiguiente infracción del principio de igualdad, cuya proclamación en nuestro ordenamiento jurídico ofrece múltiples manifestaciones" (SSTS 26 de marzo y 9 de junio de 1981 y 3 de marzo de 1983).

En el considerando $24^{\circ}$, el fallo considera asimismo la jurisprudencia de la Corte Constitucional de Colombia:

"la Constitución Politica de 1991 establece como un derecho fundamental la posibilidad de todos los asociados de acceder a las decisiones de la administración de justicia, sin limitaciones que puedan dejar truncas las posibilidades de obtener la declaración judicial de su derecho; resulta así contrario al principio de obtener pronta y cumplida justicia un precepto que impone el pago anticipado de la obligación, a juicio del deudor no debida, cuando justamente es la existencia o el monto de la misma lo que sería objeto de declaración judicial". (Sentencia No C-599/92, de 10 de diciembre de 1992).

Dicha perspectiva se repite en la sentencia Rol No 1345 de 25 de mayo de 2009.

En sentencia Rol No 1247 de 14 de julio de 2009, considerando 19o, en que se analiza el derecho de declaración o rectificación de información por los medios de comunicación social, se hace alusión a la jurisprudencia del Tribunal Constitucional español, en sentencia fechada el 22 de diciembre de 1986, en la que concluyó que:

"el derecho de rectificación asi entendido, además de su primordial virtualidad de defensa de los derechos aludidos, supone un complemento a la garantía de la opinión pública que establece también el citado precepto constitucional, ya que el acceso a una versión diferente de los hechos publicados favorece, más que perjudica, el interés colectivo de la buisqueda y recepción de la verdad que aquel derecho fundamental protege".

En sentencia Rol No 1295 de 6 de octubre de 2009, en su considerando $24^{\circ}$, se cita un párrafo de una sentencia de la Corte Suprema norteamericana que establece un principio que asume el Tribunal Constitucional en este fallo:

"24. Que sobre este punto cabe tener presente que, como lo ha señalado la jurisprudencia norteamericana, es inadmisible que una cantidad de leyes o de violaciones de la Constitución, por muchas que fueren, comporten un poder que no existe o abonen una interpretación injustificada. Una prolongada aquiescencia del Congreso o del Poder Ejecutivo, por la cual los derechos de las partes hayan sido determinados y adjudicados, no convierte en constitucional lo que es inconstitucional". (Suprema Corte de los Estados Unidos, Fairbank v. United States, 181, US 283, 307). 
En sentencia Rol No 1535 de 28 de enero de 2010, considerando 37\%, asume el principio de proporcionalidad en materia de igualdad ante la ley, en perspectiva similar a la jurisprudencia del Tribunal Constitucional español que invoca:

"37. Que, precisamente en este sentido, el Tribunal Constitucional de España ha señalado, especificamente, que para que la diferenciación resulte constitucionalmente lícita no basta que lo sea el fin que con ella se persigue, sino que es indispensable además que las consecuencias jurídicas que resultan de tal distorsión sean adecuadas y proporcionadas a dicho fin, de manera que la relación entre la medida adoptada, el resultado que produce y el fin pretendido por el legislador supere un juicio de proporcionalidad en sede constitucional, evitando resultados especialmente gravosos o desmedidos". (Sentencias 76/1990 y 253/2004). En otras palabras, como también lo ha hecho presente esta Magistratura (Roles $N{ }^{o}$. 755, 790, 1138 y 1140), la igualdad ante la ley supone analizar si la diferenciación legislativa obedece a fines objetivos y constitucionalmente válidos.

El Tribunal Constitucional en su sentencia Rol No 1365 de 8 de abril de 2010 , en su considerando $14^{\circ}$, referente al tema de registro de $\mathrm{ADN}$ en materia penal, cita en forma precisa la ratio decidendi de dos fallos de la Corte Constitucional alemana:

“(...) Como ha señalado una sentencia del Tribunal Constitucional alemán, la investigación del ámbito no codificante de la molécula de ADN tiene por objeto sólo la estructura formal de las secuencias de bases correspondientes a esas moléculas de $A D N$, las cuales no contienen información acerca de las características hereditarias del individuo (...). Conforme al estado actual del conocimiento cientifico no es evidente que mediante este tipo de investigaciones queden al descubierto las caracteristicas de la personalidad" (2 BvR 1511/96, de 2 de agosto de 1996). En una sentencia posterior, dicha Magistratura ha agregado que "es decisivo (para estimar que no se ha afectado el núcleo de la personalidad) (...) que no sea posible obtener, a través de la determinación del modelo de identificación del ADN, información o conclusiones de situaciones relevantes de la personalidad, como predisposiciones hereditarias, propiedades del carácter o enfermedades de los afectados, que permita crear un perfil de personalidad" (2 BvR 1741/99, de 14 de diciembre de 2000).

En la sentencia Rol No 1365-09 de 8 de abril de 2010, en su considerando $14^{\circ}$, el Tribunal Constitucional alude a los requisitos que deben cumplir las medidas restrictivas de derechos fundamentales, asumiendo los criterios de la jurisprudencia del Tribunal Constitucional español y del Tribunal Europeo de Derechos Humanos: 
"23. Que, con todo, la conformidad constitucional de una limitación o restricción a derechos que la propia Carta asegura no se agota en el cumplimiento de la exigencia de que ella se verifique por medio de una ley.

Asi lo han planteado el Tribunal Constitucional Español y el Tribunal Europeo de Derechos Humanos, exigiendo que las medidas restrictivas de los derechos fundamentales cumplan tres requisitos: a) que estén previstas legalmente; b) que persigan una finalidad legitima, y c) que el medio que importa la restricción sea proporcional a la finalidad perseguida (sentencias del Tribunal Europeo de Derechos Humanos 'Leander vs. Suecia'; 'Silver y otros vs. Reino Unido', 'Sunday Times con Reino Unido', y del Tribunal Constitucional español 66/1985, de 23 de mayo; 8/1992, de 16 de enero, y 207/1996, de 16 de diciembre).

Nuestra Magistratura ha sostenido, entretanto, que las restricciones o limitaciones que se imponen a un derecho fundamental deben cumplir con los siguientes requisitos: a) determinación y especificidad; b) respetar el principio de igualdad, especialmente en cuanto deben estar establecidas con parámetros incuestionables, esto es, deben ser razonables y justificadas, y c) no pueden afectar la esencia del derecho asegurado (véase, entre otras, sentencias Roles $N^{o}$ s. 226, 280, 293 y 325)".

En sentencia Rol No 557-2006 de 2 de junio de 2010, en el considerando $63^{\circ}$, se cita la jurisprudencia del Tribunal Europeo de Derechos Humanos, para compartir un enfoque de análisis sobre el tema de la disolución de partidos políticos:

"Que cabe señalar que el Tribunal Europeo de Derechos Humanos, analizando los reclamos en contra de Turquía a que hemos hecho referencia en esta sentencia, a la luz del articulo 11 de la Convención Europea de Derechos humanos, ha sostenido: que no basta el nombre del partido o movimiento para motivar la sanción de disolución (Parti Communiste Unifié de Turquie et autre c. Turquie, p. 54, y Rafah Partisi et autotes c. Turquie, p. 40); que igual razonamiento vale respecto de la ideología o doctyrina de un partido (Refah Partisi et autotes c. Turquie, p. 100); que si resulta pertinente el análisis de su programa y de sus estatutos, siempre que no se tomen en forma aislada $y$ sean corroborados por otros elementos realtivos al accionar de la organización (Refah Partisi et autotes c. Turquie, p. 101); que suele ocurrir que los verdaderos propósitos de una organización no se revelen en sus documentos oficiales y que el accionar de un partido o movimiento desmienta lo que ellos señalan; que para precisar los reales objetivos de una organización habría que analizar conjuntamente tanto sus documentos como sus actuaciones y tomas de posición (Parti Communiste Unifié de Turquie et autre c. Turquie, p. 58). Sólo así se puede concluir, según dicho Tribunal, si un partido, movimiento u organización procura un tipo de sociedad contrario a la democracia (Refah Partisi et autotes c. Turquie, p. 104)". 
En sentencia Rol No 1683-10 de 4 de enero de 2011, en su considerando $30^{\circ}$, el Tribunal Constitucional hace referencia a la jurisprudencia de la Corte Constitucional colombiana que le sirve de apoyo para asumir el enfoque de la protección de menores, acorde al "interés superior del niño" contenida en la Convención sobre Derechos del Niño:

"Este principio ha sido también recogido por la jurisprudencia de la Corte Constitucional de Colombia, según la cual: "La razón básica de esta protección a los niños y a los adolescentes son: i) El respeto a la dignidad humana que, conforme a lo previsto en el artículo $1^{o}$ de la Constitución, constituye uno de los fundamentos del Estado Social de Derecho colombiano; ii) su indefensión y vulnerabilidad, por causa del proceso de desarrollo de sus facultades y atributos personales, en su necesaria relación con el entorno, tanto natural como social, y iii) el imperativo de asegurar un futuro promisorio para la comunidad, mediante la garantía de la vida, la integridad personal, la salud, la educación y el bienestar de los mismos (sentencia C-318/03)".

En el mismo fallo, en el considerando $39^{\circ}$, se destaca la sentencia de la Corte Europea de Derechos Humanos en el caso X e Y versus Holanda (1985), concerniente a abuso sexual de una niña, de 16 años de edad y con discapacidad mental, -con consecuencias traumáticas para la víctima directa, agravando sus disturbios mentales-.

"La Corte señaló que el concepto de 'vida privada' (bajo el artículo 80 de la Convención Europea), abarcaba la integridad física y moral de la persona (inclusive su vida sexual). En el caso-agregó la Corte- 'valores fundamentales y aspectos esenciales de la vida privada' estaban en cuestión y requerian la adopción de medidas positivas por parte del Estado para asegurar el respeto por la vida privada también en la esfera de las relaciones inter-individuales. La Corte concluyó que el Estado demandado habia violado el artículo $8^{\circ}$ de la Convención por cuanto las disposiciones pertinentes del Código Penal holandés no aseguraban a la víctima una protección práctica y eficaz" (European Court of Human Rights, caso of X and Y versus the Netherlands. Judgement of 26.3.1985. Serie A No 91, pp. 11-14. Citado por la Corte Interamericana de Derechos Humanos, Opinión Consultiva OC 17/02 de 28 de agosto de 2002).

En sentencia Rol No 1656-10 y Rol No 1537-09 de $1^{\circ}$ de septiembre de 2011, en voto de prevención, cinco de los diez ministros del Tribunal Constitucional afirman el derecho a la identidad de las personas no asumido en el fallo por los otros cinco magistrados, y en su argumentación se apoyan en la jurisprudencia de la Corte Constitucional de Colombia en fallos específicos: en sentencia C-481/98, 
considerando $21^{\circ}$, la que ha considerado que el derecho a la identidad personal supone "un conjunto de atributos, de calidades, tanto de carácter biológico como los referidos a la personalidad, que permiten precisamente la individualización de un sujeto en sociedad'. Asimismo, se alude a la Corte Constitucional Colombiana, en sentencia T-477/95, considerando $15^{\circ}$, la que se considera que ha sido más explícita al considerar que "el derecho a la identidad, en cuanto determina al ser como una individualidad, comporta un significado de Dignidad Humana y en esa medida es un derecho a la libertad; tal reconocimiento permite la posibilidad de desarrollar su vida, de obtener su realización, es decir, el libre desarrollo de su personalidad". Además, se considera la sentencia de la Corte Constitucional Colombiana T-191/95, en la cual determina que "el derecho del menor a un nombre y al reconocimiento de su filiación resulta fundamental no solamente por el ya aludido mandato constitucional sino por cuanto en ello está de por medio su dignidad humana, ya que supone la posibilidad de ser identificado y diferenciado respecto de los demás individuos y el ejercicio de otros derechos, como los relativos a su alimentación, crianza, educación y establecimiento".

En sentencia Rol No 1881-10 de 3 de noviembre de 2011, en voto concurrente los ministros Venegas, Navarro y Aróstica, apoyan su criterio en su considerando $9^{\circ}$, desestimando que la regulación del matrimonio entre un hombre y una mujer definido en el artículo 102 pueda considerarse una diferencia arbitraria. En el considerando $11^{\circ}$ de su voto concurrente hacen alusión a la jurisprudencia concordante de ciertos tribunales constitucionales: del Consejo Constitucional francés que justifica la diferencia de tratamiento del matrimonio entre un hombre y una mujer de la situación de parejas del mismo sexo (sentencia 2010-92 QPC, de 28 de enero de 2011); como, asimismo, la sentencia en sentido similar de la Corte Constitucional Federal de Alemania, el cual ha determinado que la Constitución asegura el matrimonio en su respectiva fisonomía a través del legislador, y que, en todo caso, éste debe obedecer a los principios estructurales esenciales que impregnan el matrimonio, concluyendo que, de acuerdo a la jurisprudencia sostenida de ese tribunal, pertenece a lo anterior el hecho de que el matrimonio es una unión de un hombre con una mujer para una vida en conjunto y duradera (Sentencia $1 \mathrm{BvF} 1 / 01$ y $1 \mathrm{BvF} 2 / 01$, de 17 de julio de 2002).

Este tipo de citas precisas es posible identificar claramente la jurisprudencia citada y el razonamiento efectuado por el tribunal de referencia, aun cuando no siempre se conoce el contexto del caso en que se realiza la argumentación por parte del tribunal extranjero como el marco constitucional y normativo de principios y reglas específicas constitucionales en que se desarrolla el análisis jurídico del 
tribunal, los cuales son necesarios para evitar análisis descontextualizados y fuera del marco constitucional específico, el que puede ser diferente del nacional.

\subsubsection{Las citas genéricas al derecho o la jurisprudencia constitucional extranjera}

A su vez, el Tribunal Constitucional realiza referencias de tipo genérico a la jurisprudencia extranjera pudiendo señalarse como ejemplos los siguientes casos:

La sentencia Rol No 986 de 30 de enero de 2008, en su considerando $16^{\circ}$, precisa "(...) la competencia de este Tribunal limita en lo que se denomina el mérito del acto impugnado o controlado. Recordando nuevamente que en esta doctrina, "coinciden la jurisprudencia, entre otros, de los Tribunales Constitucionales de Francia, Alemania, Italia y España y las opiniones de distinguidos constitucionalistas. Tal esfera de autonomía comprende, básicamente, el conjunto de apreciaciones de mérito y oportunidad que llevan al legislador a la adopción de una u otra fórmula normativa. Sólo cuando el legislador excede su ámbito de competencia, infringiendo los márgenes contemplados en la Carta Fundamental, el Tribunal Constitucional puede intervenir para reparar los vicios de inconstitucionalidad en que éste haya incurrido".

A su vez, en la sentencia Rol No 821 de $1^{\circ}$ de abril de 2008 , en su considerando $16^{\circ}$ afirma el principio doctrinal de que "La competencia de este Tribunal limita en lo que se denomina el mérito del acto impugnado o controlado". Posición que sostiene también es asumida por la jurisprudencia, entre otros, de los Tribunales Constitucionales de Francia, Alemania, Italia y España y las opiniones de distinguidos constitucionalistas, sin mayores precisiones.

En sentencia Rol No 1029 de 10 de julio de 2008, en el considerando 5ª como un "obiter dicta", el Tribunal Constitucional ilustra con menciones de derecho extranjero la modalidad de control concreto que implica la acción de inaplicabilidad por inconstitucionalidad del artículo 93 No 6 de nuestra Constitución. Haciendo alusión a casos similares como los de Alemania, Italia y España: "Que la habilitación al juez de la causa para entablar la cuestión de inaplicabilidad por inconstitucionalidad de un precepto legal, inédita en nuestro ordenamiento jurídico, tiene como antecedente en el derecho comparado (en Alemania, Italia y España) la facultad del juez para consultar al Tribunal Constitucional las dudas de constitucionalidad que le merezca una norma jurídica".

En sentencia Rol No 1170 de 26 de agosto de 2008, en su considerando $7^{\mathrm{o}}$ se alude a los sistemas legales alemán y español en los siguientes términos: 
este Tribunal ha afirmado que "como lo señaló recientemente esta Magistratura en los autos Rol No 790-2007, el examen de la jurisprudencia de diversos Tribunales Constitucionales, como el español y el alemán, da cuenta de que no basta con que la justificación de las diferencias sea razonable sino que además debe ser objetiva".

En la sentencia Rol No 1133 de 18 de noviembre de 2008, en su considerando $17^{\circ}$ se señala: "La reciente jurisprudencia sentada por este Tribunal y compartida por otras magistraturas especializadas, como los Tribunales Constitucionales Español y Alemán, ha profundizado el punto de vista precedente señalando que el legislador puede establecer criterios que permitan situaciones fácticas que requieran de un tratamiento diverso, pero ello debe sustentarse siempre en presupuestos razonables y objetivos que justifiquen la diferencia sin que, por tanto, ella quede entregada al libre arbitrio del legislador (sentencia Rol No 790-2007)".

En la sentencia Rol No 1683-10 de 4 de enero de 2011, el voto disidente de tres ministros del Tribunal Constitucional hace uso de las referencias genéricas a la jurisprudencia de otros tribunales constitucionales extranjeros y al Tribunal Europeo de Derechos Humanos para establecer estándares internacionales respecto de relaciones homosexuales de adultos con menores de edad pero mayores de 14 años.

El voto disidente cita así la Corte de Sudáfrica, 1998, que consideró las leyes que penaban la sodomía como inconstitucionales. (Nacional Coalition of Gay \& Lesbian Equiality and others v. Minister of Justice, CTT11/98); al Tribunal Constitucional de Austria que declaró inconstitucional la norma legal que penaba la relación sexual consentida entre un varón mayor de edad y un varón menor de 18 y mayor de 14 años; la sentencia de la Corte Suprema Norteamericana Lawrence vs. Texas 539, U.S. 558, la cual señaló que la punibilidad de la sodomía consentida vulnera el derecho a la intimidad de las personas y el derecho a la igualdad; el tribunal superior en India, en 2009, que consideró que la penalización de la conducta homosexual es ilegítima. A su vez, cita las sentencias del Tribunal Europeo de Derechos Humanos que, en 1981, sancionó a Inglaterra por penalizar conductas homosexuales consentidas entre adultos donde uno era menor de 21 años. (Dudgeon vs. United Kindom); que en 1986 condena a Irlanda por penalizar la sodomía (Norris vs. Irlanda, 1987); que, en 1993, reiteró los argumentos al condenar a Chipre (Modinos vs. Chipre, 1993), y que en 2003 condenó a Austria por tipificar como delitos conductas homosexuales entre personas mayores de 14 y menores de 18 (L.V. vs. Austria, 2003). 
En cita amplia, en el fallo Rol No 1881-10 de 3 de noviembre de 2011, el voto concurrente de los Ministros Carmona, Fernández Fredes, García y Viera Gallo, tienen presente que los diversos países que han debido enfrentar decisiones como la que corresponde considerar al Tribunal Constitucional en el presente caso, han considerado lo dispuesto por sus constituciones y las regulaciones o no de las uniones de hecho. En su motivación, en el considerando $3^{\circ}$ de su voto concurrente, los ministros hacen presente que su argumento coincide con lo resuelto por el Tribunal Europeo de Derechos Humanos, en el caso Schalk and Kopf contra Austria, de junio de 2010; y con lo establecido por la Corte Constitucional de Colombia de 2011. En ambos casos se señaló que el derecho a formar una familia es independiente del derecho a contraer matrimonio, y que la vida familiar se puede desarrollar fuera del ámbito matrimonial, por lo que el impedimiento de contraer matrimonio para personas de igual sexo en sí mismo no vulneran el derecho a formar una familia. A su vez, consideran la sentencia del Consejo Constitucional Francés de enero de 2011, donde se pronunció sobre la exclusión de dos disposiciones del código que excluían el matrimonio de personas del mismo sexo, en ella el Consejo Constitucional consideró que el artículo 34 de la Constitución otorga al legislador la competencia para regular los regimenes matrimoniales y, en general, las materias de familia; que la estipulación del matrimonio entre un hombre y una mujer no afecta el desarrollo de la vida personal o familiar, pues existen en Francia otras regulaciones legales que permiten la convivencia entre personas del mismo sexo, como la ley que establece el Pacto de Solidaridad, como, asimismo, es de competencia del parlamento la elección del sistema más adecuado para la plena realización de las personas que tienen preferencias sexuales por sujetos de su mismo sexo (C 9, 2010-92 QPC, de 28 de enero de 2011).

Estas citas genéricas presentan el inconveniente en muchos casos de la imposibilidad de poder comprobar el aserto recurriendo a la fuente citada, ya que se carece de antecedentes suficientes para poder ubicarla con la información entregada en el fallo; en otros casos, los antecedentes entregados de la jurisprudencia señalada implican afirmaciones desprovistas de un contexto argumentativo en que se desarrollaron y del marco constitucional específico del respectivo país, con lo que incluso, la misma sentencia es utilizada para argumentar enfoques diferentes y a veces contradictorios. Lo mismo ocurre con sentencias de tribunales como ocurre con la sentencia Rol No 1881-10 de 3 de noviembre de 2011 en que se cita la sentencia de la Corte Europea de Derechos Humanos de 24 de junio de 2010, en el caso Schalk and Kopf v. Austria, a través de votos particulares o prevenciones de diversos ministros. 


\subsubsection{Las citas indirectas a la jurisprudencia constitucional extranjera}

Otra manera de cita del Tribunal Constitucional es aquella de carácter indirecto, en la cual el Tribunal Constitucional concreta citas de jurisprudencia de tribunales constitucionales de otros países a través de obras de doctrina constitucional de autores extranjeros.

Así, a manera ejemplar, pueden citarse los siguientes casos:

La sentencia Rol No 1361 de 13 de mayo de 2009, cuyo considerando $18^{\circ}$ se remite a la jurisprudencia de algunos tribunales constitucionales europeos, los cuales cita indirectamente mediante la consideración de bibliografía jurídica de autores franceses y alemanes:

"18.- Que dicho principio constituye una regla básica adoptada explícitamente por los más importantes Tribunales Constitucionales de Europa. Asi, por ejemplo, el Consejo Constitucional Francés ha declarado su incompetencia para emitir pronunciamientos sobre cuestiones de mérito, consignando que la Constitución no le confiere al Consejo Constitucional un poder general para juzgar y decidir idéntico a aquél del Parlamento. Sólo le entrega competencia para decidir si una ley sometida a su control es consistente o no con la Constitución' (Vid. David Dokhan, Les limites du contròle de la constitutionnalité des actes législatifs, 2001, Librairie Générale de Droit et de Jurisprudence, especialmente páginas 450 y siguientes). El Tribunal Constitucional español, por su parte, ha precisado que: 'La Constitución, como marco normativo, suele dejar al legislador márgenes más o menos amplios dentro de los cuales aquél puede convertir en ley sus preferencias ideológicas, sus opciones politicas y sus juicios de oportunidad'. En el mismo sentido, como lo ha consignado el Tribunal Constitucional alemán, el legislador goza de un espacio de reglamentación, valoración y examen propio que, en principio, no puede ser revisado por los tribunales (Sentencia de la Segunda Sala, 29 de octubre de 1987, Tomo 77, página 170 II, en 50 años de Jurisprudencia del Tribunal Constitucional Federal Alemán, Jürgen Schwabe, 2003, p. 92)".

En sentido similar, se encuentra la sentencia del Tribunal Constitucional Rol No 1365 , de 8 de abril de 2010, considerando $19^{\circ}$, en la cual hace referencia genérica a países que cuentan con registros de $\mathrm{ADN}$ y las variables que justifican la utilidad de tales archivos, extraídos de una autora que ha escrito sobre la materia:

"19.- Que, desde el punto de vista del derecho comparado, es posible observar que ya son numerosos los países que cuentan con Registros de ADN (Inglaterra, Irlanda, Escocia, Holanda, Austria, Alemania, Eslovenia, Noruega, Finlandia, Dinamarca, Suiza, Suecia, Croacia, Bélgica, Francia, República Checa, Estonia, Lituania, Eslovaquia y Hungría, tan 
sólo en Europa), en los cuales suelen utilizarse tres variables que justifican la utilidad del archivo en forma compatible con el respeto de los derechos constitucionales involucrados: a) la gravedad delictual; b) que sean delitos con un alto nivel de reincidencia; y c) la posibilidad de que en la comisión de ese delito se dejen vestigios biológicos, como ocurre con los delitos sexuales (Guillén Vázquez, Margarita. Ob. cit.)”.

Tal perspectiva la encontramos también en la sentencia Rol No 567 de 3 de junio de 2010 , en su considerando $28^{\circ}$, el que se refiere a través de un texto académico citado a la jurisprudencia del Tribunal Constitucional español en materia de libertad de conciencia y libertad ideológica:

"Vigésimo octavo. (...) La libertad de conciencia, o ideológica, constituye uno de los pilares del Estado de Derecho. Al respecto, el Tribunal Constitucional Español ha señalado que '(s)in libertad ideológica (...), no serían posibles los valores superiores de nuestro ordenamiento jurídico que se propugnan en el artículo 1.1., de la misma, para constituir el Estado de Derecho que en dicho precepto se instaura. Para que la libertad, la justicia, la igualdad y el pluralismo politico sean una realidad efectiva y no una enunciación teórica de unos principios ideales, es preciso que a la hora de regular conductas $y$, por tanto, de enjuiciarlas, se respeten aquellos valores superiores sin los cuales no se puede desarrollar el régimen democrático que nos hemos dado en la Constitución de 1978'. (STC 20/1990, FJ 30, citada por Pérez Royo, Javier. Curso de Derecho Constitucional. Marcial Pons. Ediciones Jurídicas y Sociales S.A. Décima edición, Madrid, 2005, p. 329)".

Otra sentencia en que se utiliza la referencia indirecta a la jurisprudencia de un Tribunal Constitucional es el fallo Rol No 1576-09 de 16 de diciembre de 2010 , en su considerando $28^{\circ}$, en el cual se distingue la nueva aproximación de la Corte Constitucional alemana al tema de la igualdad, con las igualdades y desigualdades esenciales, a través de la obra de Alexy:

"Vigésimo octavo: Que esta Magistratura se ha pronunciado repetidamente respecto del contenido de la citada disposición constitucional, como lo hizo en la sentencia de inconstitucionalidad recaida en la causa Rol No 1710-10, de fecha 6 de agosto de 2010. A través de tal jurisprudencia esta Magistratura ha dado cuenta del extenso esfuerzo jurídico conceptual desplegado en la doctrina para definir la igualdad ante la ley, desde la famosa y reiterada fórmula platónica y aristotélica de 'tratar igual a lo igual y desigual a lo desigual', hasta su moderna diferenciación postulada por el Tribunal Constitucional alemán para el examen de arbitrariedad, sustentada en las igualdades y desigualdades esenciales, según la cual al legislador le está prohibido tratar: 'a) lo igual desigualmente, b) lo esencialmente igual desigualmente, y c) lo esencialmente igual arbitrariamente desigual'; a lo que el autor Robert Alexy agrega, entre otras conclusiones, que 'existe una igualdad esencial si 
y sólo si un tratamiento desigual sería arbitrario (Robert Alexy: Teoría de los Derechos

Fundamentales, Centro de Estudios Constitucionales, Madrid, pp. 389-391)”.

En algunos casos estas citas son precisas y en otros casos ellas son genéricas, presentando las situaciones propias de cada uno de estos tipos de citas ya mencionadas.

\subsection{La consideración de la referencia al derecho constitucional o la extranjera como parte de la ratio decidendi o como obiter dicta del fallo}

En este párrafo analizaremos la existencia de algunos casos en que sentencias del Tribunal constitucional chileno utiliza jurisprudencia de tribunales internacionales no vinculantes para Chile, como jurisprudencia de otros tribunales constitucionales extranjeros ya sea como ratio decidendi o como obiter dicta de los fallos.

\subsubsection{La consideración de la jurisprudencia constitucional extranjera o internacional no vinculante como elemento que contribuye a la ratio decidendi de la sentencia}

El uso de los razonamientos de la jurisprudencia constitucional extranjera y de tribunales internacionales no vinculantes para el Estado de Chile, ha posibilitado desarrollar postulados de interpretación, enfoques metodológicos de razonamiento jurídico que pasan a constituir elementos de la ratio decidendi del Tribunal Constitucional chileno.

A continuación señalaremos algunos casos significativos en este ámbito.

La Sentencia Rol No 790 de once de diciembre de 2007, en que se analiza la posible discriminación en materia de pensiones, el Tribunal Constitucional para determinar si las diferencias de trato entre las distintas categorías de pensionados reguladas por preceptos legales son constitucionalmente tolerables, recurre a la jurisprudencia constitucional comparada y considera, apoyándose en la jurisprudencia constitucional de Alemania, España y México, utilizar el postulado o principio de proporcionalidad para analizar la conformidad de la norma legal restrictiva del derecho a la igualdad.

En Roles No 755-2007, No 986-2008, No 1217 de 2009, No 1204 de 2009, No 1340 de 2009, Rol No 1535 de 28 de enero de 2010, Rol No 1365 de ocho de abril de 2010, Rol No 1399-09 de cuatro de noviembre de 2010, Rol No 1656-10 de $1^{\circ}$ de septiembre de 2011; el Tribunal Constitucional asume bajo la perspectiva de la jurisprudencia comparada, especialmente alemana y es- 
pañola, el enfoque interpretativo que el legislador, en ejercicio de sus potestades, puede establecer regímenes especiales, diferenciados y desiguales siempre que ello no revista el carácter de arbitrario. Asimismo, se afirmará que las desigualdades de trato contrarias al principio de igualdad, son sólo aquellas que se fundan en supuestos de hecho injustificados de acuerdo con criterios o juicios de valor generalmente aceptados.

En sentencia Rol No 1288 del veinticinco de agosto de 2009, respecto del control preventivo obligatorio de constitucionalidad de la Ley Orgánica Constitucional del Tribunal Constitucional se establece:

"68: Que, por lo demás, según se desprende de los antecedentes de la historia fidedigna del proyecto, la norma constitucional tiene su origen en lo que dispone el artículo 96.1 de la Constitución Española, que señala: "Los tratados internacionales válidamente celebrados, una vez publicados oficialmente en España, formarán parte del ordenamiento interno. Sus disposiciones sólo podrán ser derogadas, modificadas o suspendidas en la forma prevista en los propios tratados o de acuerdo con las normas generales del Derecho Internacional", y afirmándose en la doctrina de un solo autor español, Manuel Diez de Velasco, el cual considera que el Tribunal Constitucional puede declarar inaplicable (nulidad puramente interna) un tratado, pues la nulidad de un Tratado sólo puede fundarse en las causas previstas en el Derecho Internacional (art. 42.1 del Convenio de Viena sobre el Derecho de los Tratados) y no puede ser declarado(a) unilateralmente por una de las Partes".

A su vez, el Tribunal Constitucional considera también el artículo 100 de la Ley Fundamental de Alemania de acuerdo con su artículo 25. Criterio en base al cual refuerza su posición de que los tratados pueden ser objeto de inaplicabilidad por inconstitucionalidad de acuerdo al artículo 96 No 3 , con la disidencia de cuatro Ministros del Tribunal, que estiman que ello no es procedente en el Derecho Constitucional chileno, entre otras razones por ser las competencias del Tribunal Constitucional tasadas y no encontrarse entre ellas, el control reparador de constitucionalidad de tratados, sino sólo un control preventivo de ellos.

En sentencias Roles No 755-2007 y No 790-2007, Roles No 1217 y No 1204 de 2009, Roles No 1535 de 2010, Rol No 1414 de 2010, el Tribunal Constitucional asume, en base al examen de la jurisprudencia de diversos Tribunales Constitucionales, como el español y el alemán, el que no basta con que la justificación de las diferencias sea razonable sino que además debe ser objetiva, doctrina que es asumida por el Tribunal Constitucional en la ratio decidendi de los respectivos fallos. 
En sentencia Rol No 1881-10 de 3 de noviembre de 2011, el voto particular de tres ministros del Tribunal (Srs. Aróstica, Navarro y Venegas) considera el criterio asumido por el Consejo Constitucional francés de que el principio de igualdad no se opone ni impide que el legislador regule de forma distinta situaciones diferentes, ni que se derogue la igualdad por motivos de interés general, siempre que, en uno y otro caso, la diferencia de trato tenga directa relación con el objeto que la ley persigue, que, manteniendo el principio según el cual el matrimonio es la unión de un hombre y una mujer, el legislador ha estimado, en el ejercicio de la competencia que le atribuye el artículo 34 de la Constitución (francesa), que la diferencia de situaciones entre las parejas del mismo sexo y las parejas compuestas por un hombre y una mujer puedan justificar una diferencia de tratamiento en cuanto a las normas del derecho de familia (sentencia 2010-92 QPC, de 28 de enero de 2011). Si bien este voto particular rechaza la inconstitucionalidad del artículo 102 del Código Civil sobre el matrimonio heterosexual entre un hombre y una mujer, no afirma ni niega que parejas homosexuales puedan estar protegidas por el ordenamiento jurídico, lo que de acuerdo a la Constitución corresponde determinar al legislador y no al Tribunal Constitucional.

En su voto particular, la Ministra Marisol Peña, considera en su razonamiento la sentencia de la Corte Europea de Derechos Humanos de 24 de junio de 2010, en el caso Schalk and Kopf v. Austria, donde se sostuvo que "el artículo 12 (de la Convención Europea de derechos Humanos) no impone a los Estados contratantes una obligación de garantizar a las parejas del mismo sexo el acceso al matrimonio. El artículo 14 tomado en conjunción con el artículo 8, otorgan una provisión de un propósito y alcance más amplio, que no puede ser interpretada como la imposición de una obligación (consid. 101)”. De lo que desprende que el legislador está autorizado para configurar legislativamente el matrimonio, debiendo hacerlo de acuerdo con los valores y principios expresados constitucionalmente.

En el voto particular de los ministros Fernández, Carmona, Viera-Gallo y García, considera la jurisprudencia del Consejo Constitucional francés en sentencia 2010-92 QPC, considerando 9o, que estima que corresponde al parlamento regular el sistema más adecuado para la plena realización de las personas que tienen preferencias por personas del mismo sexo; perspectiva que es asumida también por el Tribunal Europeo de Derechos Humanos, en sentencia de 28 de enero de 2011, en el caso Schalk and Kopfv. Austria, y la Corte Constitucional de Colombia en sentencia de julio de 2011, lo que les parece una metodología adecuada para analizar el caso que debe resolver el Tribunal 
Constitucional chileno, llegando a la misma conclusión en el caso chileno que la que llegaron los órganos de jurisdicción constitucional antes señalados. Dicho voto particular considera además que el sexo o condición sexual constituye un criterio sospechoso de discriminación, lo que puede transformarse en una categoría contraria a la igualdad ante la ley cuando manifieste el propósito de hostilidad contra determinadas personas o grupo de personas.

En sentencia Roles No 1273 de 2010; considerando 60; No 1348 de 2010, considerando 46; No 1710 de 2010; No 1419-09 de nueve de noviembre de 2010, se asume a través de la consideración de fallos de la Corte Constitucional de Karlsruhe el enfoque sobre igualdades esenciales y desigualdades esenciales, la que se aplica al caso específico que debe resolver el Tribunal Constitucional. En efecto, la sentencia rol No 1273 de 2010, en su considerando 60 determina:

"Que, por la reputación que ha tenido en el derecho comparado, es menester tener en consideración, para dilucidar el caso de autos, el cuerpo doctrinal y el método que la doctrina y la jurisprudencia alemanas de las últimas décadas han desarrollado para afrontar los problemas descritos. Según tal enfoque, es necesario distinguir conceptualmente entre 'igualdades esenciales'y 'desigualdades esenciales'. Así, estamos en presencia de una igualdad esencial cuando 'personas, grupos de personas o situaciones, sobre la base de un punto de partida (tertium comparationis), son comparables'. Consecuentemente, el Tribunal Constitucional Federal alemán ha decidido que la Ley Fundamental considera arbitrario, y por ende inconstitucional, tratar desigualmente a las igualdades esenciales, así como tratar igualmente a las desigualdades esenciales. Además, se agrega la denominada 'nueva fórmula', consistente en considerar lesionada la igualdad ante la ley cuando un grupo de destinatarios de la norma, comparados con otro grupo de destinatarios de la norma, son tratados de manera distinta, a pesar de que entre ambos grupos no media ninguna diferencia de tal entidad o importancia que pudiera justificar un tratamiento desigual. Para poder dimensionar tales situaciones, esta fórmula requiere expresamente una ponderación en el sentido de examen de proporcionalidad, especialmente respecto de una diferencia de trato de gran intensidad, para lo cual se requiere que aquélla persiga un fin legítimo, que esa búsqueda sea necesaria y que presente una razonable relación con el valor del fin propuesto (Rolf Schmidt: Grundrechte (sowie Grundzüge der Verfassungsbeschwerde) [Derechos Fundamentales. Lineamientos de Recursos Constitucionales, Verlag Dr. Rolf Schmidt, Grasberg, 2005, pp. 177-178];”.

En la sentencia Rol No 1365 de 8 de abril de 2010, en su considerando $14^{\circ}$, el Tribunal Constitucional asume los requisitos que deben cumplir las medidas restrictivas de derechos fundamentales, de usual utilización por la jurisprudencia 
del Tribunal Europeo de Derechos Humanos y del Tribunal Constitucional Español:

"23. Que, con todo, la conformidad constitucional de una limitación o restricción a derechos que la propia Carta asegura no se agota en el cumplimiento de la exigencia de que ella se verifique por medio de una ley.

Asi lo han planteado el Tribunal Constitucional español y el Tribunal Europeo de Derechos Humanos, exigiendo que las medidas restrictivas de los derechos fundamentales cumplan tres requisitos: a) que estén previstas legalmente; b) que persigan una finalidad legitima, y c) que el medio que importa la restricción sea proporcional a la finalidad perseguida (sentencias del Tribunal Europeo de Derechos Humanos 'Leander vs. Suecia'; 'Silver y otros vs. Reino Unido', 'Sunday Times con Reino Unido', y del Tribunal Constitucional español 66/1985, de 23 de mayo; 8/1992, de 16 de enero, y 207/1996, de 16 de diciembre)".

En Sentencia Rol No 1247 del catorce de julio de 2009, el Tribunal Constitucional asume en la ratio decidendi de un fallo del Tribunal Constitucional Español de 22 de diciembre de 1986, sobre el derecho de rectificación, el cual cita: "en cuanto a su alcance, el Tribunal Constitucional español, en sentencia fechada el 22 de diciembre de 1986, concluyó que 'el derecho de rectificación así entendido, además de su primordial virtualidad de defensa de los derechos aludidos, supone un complemento a la garantía de la opinión pública que establece también el citado precepto constitucional, ya que el acceso a una versión diferente de los hechos publicados favorece, más que perjudica, el interés colectivo de la búsqueda y recepción de la verdad que aquel derecho fundamental protege'”. Ello permite afirmar al Tribunal Constitucional que el derecho de rectificación o declaración asegurado constitucionalmente en el artículo 19 No 12 de nuestra Constitución "se trata de un derecho que se vincula no sólo al honor y la honra de la persona sino que también se relaciona con la veracidad de la información" (considerando $19^{\circ}$ ).

En Sentencia rol No 567 de dos de junio de dos mil diez, el Tribunal Constitucional chileno en su sentencia sobre el requerimiento de inconstitucionalidad del Movimiento Patria Nueva Sociedad, desarrolla un enfoque metodológico e interpretativo para analizar la materia que se extrae en parte importante de la jurisprudencia del Tribunal Europeo de Derechos Humanos. En efecto, el Tribunal Europeo de Derechos Humanos en los dos casos contra Turquía por haber declarado inconstitucionales el "Partido Comunista Unificado" y el "Partido de la Prosperidad" (Refah), sostuvo que al resolver este tipo de materias el Tribunal debe procurar una cierta forma de conciliación entre las exigencias de defensa 
de la sociedad democrática y la salvaguarda de los derechos individuales, que el Tribunal Constitucional chileno hace suya (considerando noveno). A su vez, se asume por parte del Tribunal citando la misma jurisprudencia ya señalada en el sentido de que "la protección de las opiniones y la libertad de expresarlas constituye uno de los objetivos de la libertad de reunión y asociación” asume que el derecho de asociación guarda una estrecha vinculación con otros derechos constitucionales (considerando 25\%), lo que es expresión del principio de unidad de la Constitución (considerando 26ㅇ). A su vez, también hace suyo el criterio interpretativo del Tribunal Europeo de Derechos Humanos, de que las limitaciones del derecho a la libertad de expresión no pueden afectar ideas aunque "irriten, alarmen, sorprendan o inquieten a las autoridades", citando las dos sentencias turcas antes señaladas, como asimismo, una referencia general a la Corte Interamericana de Derechos Humanos considerando 36º). El Tribunal Constitucional también asume la perspectiva sostenida por la jurisprudencia del Tribunal Europeo de Derechos Humanos en el sentido de que la libertad de expresión no da cobertura al "discurso del odio", que es aquel que incita directamente a la violencia contra los ciudadanos en general o determinadas razas, o creencias en particular, citando las sentencias Ergodu e Ince c. Turquía, de 8 de julio de 1999; Gündüz c. Turquía de 4 de diciembre de 2003, y Erbakan $c$. Turquía, de 6 de julio de 2006, en su considerando $38^{\circ}$.

El Tribunal Constitucional asume el estándar de que el sentido y alcance del ilícito constitucional analizado no puede ser otro que el de una norma excepcional destinada a sancionar casos particularmente graves en que organizaciones políticas atenten seriamente contra los principios de la Constitución con cita al Tribunal Europeo de Derechos Humanos que ha determinado " que los partidos políticos representan una forma de asociación esencial para el buen funcionamiento de la democracia. Toda medida adoptada en su contra afecta a la vez la libertad de asociación y el estado de la democracia del país donde ocurre (Refah Partisi et autres c. Turquie, p. 87), como precisa el considerando $45^{\circ}$. Complementariamente el Tribunal Constitucional también asume el enfoque interpretativo desarrollado por el Tribunal Europeo de Derechos Humanos de que toda restricción de la libertad de asociación supone una interpretación estricta según el artículo 11 de la Convención Europea de Derechos Humanos, el cual deja a las autoridades nacionales un margen reducido de decisión. La declaración de una organización política como inconstitucional sólo podría tener lugar en los casos más graves, como ultima ratio, frente a un riesgo o amenaza real para la Constitución, como se determina en el considerando $51^{\circ}$. En la misma perspec- 
tiva el Tribunal Constitucional chileno cita al Tribunal Europeo de Derechos Humanos, analizando los reclamos contra Turquía, a la luz del artículo 11 de la Convención Europea de Derechos Humanos, el cual esboza algunos criterios que son asumidos y compartidos por nuestro Tribunal, en el sentido que no basta el nombre del partido o movimiento para motivar la sanción de disolución, que igual razonamiento vale respecto de la ideología o doctrina de un partido, que si resulta pertinente el análisis de su programa y de sus estatutos, siempre que no se tomen en forma aislada y sean corroborados por otros elementos relativos al accionar de la organización; que suele ocurrir que los verdaderos propósitos de una organización no se revelen en sus documentos oficiales y que el accionar de un partido o movimiento desmienta lo que ellos señalan; que para precisar los reales objetivos de una organización habría que analizar conjuntamente tanto sus documentos oficiales como sus actuaciones y tomas de posición. Sólo así se podría concluir, según dicho Tribunal. Si un partido, movimiento u organización procura un tipo de sociedad contrario a la democracia, como establece el considerando $63^{\circ}$. Estas consideraciones, señala el Tribunal Constitucional, resultan cruciales y las considera metodología que el Tribunal Constitucional aplica al caso específico que debe resolver.

En sentencia Rol No 1683-10, el Tribunal Constitucional considera que el artículo 365 del Código Penal no vulnera la igualdad ante la ley, el principio de no discriminación, la protección de la vida privada y la intimidad, ni el contenido esencial de tales derechos, en la medida que el legislador ha protegido el interés superior del menor a su indemnidad sexual protegiéndolo de relaciones sodomíticas, en virtud de su indefensión o vulnerabilidad, afincada en la inmadurez de su desarrollo psíquico y sexual. Para ello asume el enfoque argumentativo desarrollado por la Corte Constitucional de Colombia, en su sentencia C-318/03. Por su parte, respecto de la eventual intromisión en la vida privada, asume la doctrina del Tribunal Europeo de Derechos Humanos en el caso Diane Pretty de 2006, en que el Tribunal precisa que la privacidad no alcanza a las conductas criminales, aún consentidas; como también la Jurisprudencia del Supremo Tribunal Federal de Brasil que afirma que la privacidad no es un derecho absoluto que pueda ser utilizado como garantía a la permisión de delitos sexuales; y, finalmente, la sentencia del Tribunal Europeo de Derechos Humanos en el caso Xe Y versus Holanda (1985) que consideró que el concepto de vida privada abarcaba la integridad física y moral de la persona, incluyendo su vida sexual, debiendo el Estado desarrollar una protección práctica y eficaz de tales dimensiones del derecho respecto de abusos sexuales de una víctima menor, con disturbios 
mentales, condenando a Holanda porque su Código Penal no aseguraba a la víctima una protección práctica y eficaz. A su vez, en un voto de prevención se precisa el amplio margen de apreciación con que cuenta el legislador para valorar y configurar a través de la legislación el ordenamiento jurídico.

A su vez, el voto de minoría de cuatro ministros utiliza también como parte del enfoque metodológico de análisis el estándar establecido por la jurisprudencia de diversas jurisdicciones constitucionales de Sudáfrica, Austria, Estados Unidos e India y de diversas sentencias del Tribunal Europeo de Derechos Humanos para sustentar su criterio interpretativo, de que la penalización de la sodomía consentida es inconstitucional, como también es inconstitucional la sanción penal de dicha conducta respecto de personas del mismo sexo y no para heterosexuales, estableciendo en la tipificación del ilícito penal edades diferenciadas entre un caso u otro, discriminando así entre unos y otros, además de afirmar la existencia de una injerencia indebida en la vida privada de tales personas.

En sentencia Rol No 1656-10 y Rol No 1537-09 de $1^{\circ}$ de septiembre de 2011, en que el Tribunal Constitucional cita el criterio sostenido por el Tribunal Constitucional español en su jurisprudencia, que es el mismo que utiliza en la ratio decidendi de la sentencia, sosteniendo que la acción de inaplicabilidad por inconstitucionalidad resulta viable porque el órgano judicial duda efectivamente de la constitucionalidad de un precepto legal a cuyo tenor literal se encuentra sujeto, sin que el hecho de que sea posible una interpretación de la norma cuestionada conforme con la Constitución, no permita considerar a la cuestión como mal fundada.

\subsubsection{El uso de la jurisprudencia constitucional y el derecho constitucional extranjero como parte de los obiter dicta del Tribunal Constitucional}

En muchas oportunidades el Tribunal Constitucional utiliza la jurisprudencia de jurisdicciones constitucionales extranjeras como parte de los obiter dicta de sus sentencias, las cuales sólo ilustran sobre la existencia de razonamientos, instituciones o enfoques de jurisprudencia de otros países o en otros casos son consideraciones superfluas que no aportan nada al razonamiento jurisdiccional desarrollado.

Algunos ejemplos de este tipo de uso de la jurisprudencia o del derecho constitucional extranjero son los siguientes:

En fallo Rol No 480 de 27 de julio de 2006, en requerimiento formulado por Energía IBENER S.A., el Tribunal Constitucional resuelve que el principio de legalidad del derecho sancionador debe aplicarse igualmente en materia penal, 
como en materia administrativa sancionadora. En los votos concurrentes de los ministros Marcelo Venegas Palacios y Enrique Navarro Beltrán, estos establecen, para reforzar su argumentación jurídica, el uso de jurisprudencia del Tribunal Constitucional Español, extraída de una conocida obra de derecho administrativo español:

"que los principios de legalidad y tipicidad que inspiran el orden penal y que se encuentran recogidos en los tres últimos incisos del No 3 del artículo 19 se aplican también a todas las manifestaciones del derecho sancionador del Estado, utilizando para ello, como elemento de apoyo y de refuerzo la jurisprudencia del Tribunal Constitucional Español, citada por doctrina española:

"Que estos principios imponen, en palabras del Tribunal Constitucional español, la exigencia material absoluta de predeterminación normativa de las conductas y de las sanciones correspondientes, exigencias que (...) afecta a la tipificación de las infracciones, a la graduación y escala de las sanciones y a la correlación entre unas y otras, de tal modo que (...) el conjunto de las normas aplicables permita predecir, con suficiente grado de certeza, el tipo y el grado de sanción susceptible de ser impuesta. (T. Constitucional de España, sentencia de 29 de marzo de 1990, citada en García de Enterria, Eduardo y Fernández, Tomas-Ramón, Derecho Administrativo, p. 177)”.

El Tribunal Constitucional en sentencia Rol No 549 de treinta de marzo de 2007, razona sobre el principio de tipicidad y refuerza su argumentación apelando a la jurisprudencia del Tribunal Constitucional Español:

"En tal sentido, el Tribunal Constitucional Español, en sentencia No 89, de 12 de marzo de 1993, ha precisado lo siguiente: 'Es claro que el legislador penal no viene constitucionalmente obligado a acuñar definiciones especificas para todos y cada uno de los términos que integran la descripción del tipo. Si se tiene presente lo que queda dicho en el fundamento que antecede -esto es, la inserción de toda norma en el sistema que es el ordenamiento-, una tal labor definitoria sólo resultaría inexcusable cuando el legislador se sirviera de expresiones que por su falta de arraigo en la propia cultura juridica carecieran de toda virtualidad justificante y deparasen, por lo mismo, una indeterminación sobre la conducta delimitada mediante tales expresiones".

En sentencia Rol No 523 de diecinueve de junio de 2007, el Tribunal Constitucional utiliza la jurisprudencia del Tribunal Constitucional español para reforzar su línea argumental sobre el sentido y alcance de la autonomía universitaria.

En sentencia Rol No 616 de seis de septiembre de 2007, el Tribunal Constitucional ilustra sobre la existencia de diferentes modelos de justicia administrativa en el Derecho Constitucional europeo y americano en su considerando 
vigésimo sexto, ello le permite concluir que, como ocurre en algunos casos del derecho comparado, en el ordenamiento jurídico chileno es legítimo que la autoridad administrativa puede ejercer funciones de carácter jurisdiccional, como precisa en su considerando vigésimo noveno.

En sentencias Rol No 664 de 2007, Rol No 1029 de 2008, Roles No 1140, No 1361 y No 1295 de 2009, en diversas peticiones de inaplicabilidad por inconstitucionalidad, el Tribunal Constitucional asume la concepción de la ilegitimidad que tiene para pronunciarse sobre consideraciones de mérito, refuerza su tesis utilizando para ello jurisprudencia de tribunales constitucionales europeos: el Consejo Constitucional francés y los tribunales constitucionales de España e Italia, no siendo ello el tema central sobre el que debe pronunciarse el fallo y en algunos casos de dudosa aplicación en virtud de los estándares permitidos de restricción de derechos.

En sentencia Rol No 718 de 2007, el Tribunal Constitucional hace alusión a jurisprudencia y derecho constitucional extranjero norteamericano y europeo para sostener, que al igual que ellos en Chile hay reserva de ley en la materia, pero ello no excluye la posibilidad de que las leyes contengan remisiones a normas reglamentarias, las cuales no pueden hacer posible una regulación independiente y no claramente subordinada a la ley.

En sentencia Rol No 759 de 2007, el Tribunal Constitucional vuelve a remitirse al derecho constitucional extranjero y la jurisprudencia extranjera, para sostener que éstos al igual que en Chile "los elementos esenciales de la obligación tributaria deben quedar fijados suficientemente en la ley, no pudiendo efectuarse remisiones vagas y genéricas a la potestad reglamentaria de ejecución”. Asimismo, refuerza su criterio señalando jurisprudencia en el mismo sentido del Tribunal Constitucional español.

En sentencia Rol No 576 de veinticuatro de abril de 2007, el Tribunal Constitucional determina que el precepto legal no contempla la prisión por deudas, sino que una apropiación indebida del empleador de dineros que son propiedad de los trabajadores, donde sin perjuicio de analizar las normas de la CADH y del PIDCyP, considera también la jurisprudencia Tribunal Constitucional español, el cual ha sentenciado que "sólo puede hablarse con propiedad de prisión por deudas cuando la insolvencia tiene su base en el incumplimiento de una obligación contractual" (230/1991).

En sentencias Rol No 775 de 2007, Rol No 1138 de 2008, Rol No 1140 de 2009 y Rol No 1254 del veintinueve de julio de 2009, en requerimiento de inaplicabilidad presentado respecto del artículo 595 del Código Orgánico 
de Tribunales, sobre el desarrollo de la labor de abogado de turno gratuito, el Tribunal Constitucional ilustrará con ejemplos de derecho comparado de Italia, España y Francia, en su considerando 43ㅇ, como de alguna jurisprudencia latinoamericana, Sala Constitucional de la Corte Suprema de Justicia de Costa Rica (Res. 06420-98), como, asimismo, de alguna jurisprudencia del Tribunal Europeo de Derechos Humanos, en sentencia de 23 de noviembre de 1983, caso Van der Músele, para concluir que si bien no es cuestionable constitucionalmente nombrar un defensor de oficio, no resulta razonable ni proporcionado que este no reciba remuneración por el trabajo desarrollado.

En sentencia Rol No 1216 de 2008, el Tribunal Constitucional precisa que en el Derecho Constitucional comparado se ha tenido en consideración el papel trascendente reservado a los reglamentos parlamentarios en el régimen político, por lo que diversos ordenamientos jurídicos, como el francés y el español, han otorgado a sus respectivos Tribunales Constitucionales la facultad de pronunciarse sobre su sujeción a la Ley Suprema, lo que no ocurre en el caso chileno, donde el artículo 93 de la Carta Fundamental determina taxativamente la jurisdicción y atribuciones del Tribunal Constitucional, dentro de las cuales no se encuentra en control de reglamentos parlamentarios, además el artículo $7^{\circ}$ de la Constitución impide al Tribunal Constitucional ir más allá del ejercicio de las competencias que le están expresamente atribuidas, como dispone el considerando $12^{\circ}$.

En sentencia Rol No 1029 de 2008, el Tribunal Constitucional hace alusión al derecho constitucional de Alemania, Italia y España, señalándolos como precedentes de la regulación de la acción de inaplicabilidad por inconstitucionalidad instituida en el artículo 93 No 6 de la Constitución

En sentencia Rol No 740, en requerimiento de inconstitucionalidad deducido en contra de algunas disposiciones de las "Normas Nacionales sobre Regulación de la Fertilidad", aprobadas por el Decreto Supremo No 48, de 2007, del Ministerio de Salud. El Tribunal Constitucional utiliza como elemento complementario de su razonamiento, en el considerando $37^{\circ}$, la alusión a la Información del diario El País, de España, el 9 de abril de 2008, indica que "el Consejo de Estado francés veta 'la pildora del día después' en la escuela" aludiendo a la decisión de ese órgano de control de los actos de la Administración que ha impedido que el mencionado fármaco (norlevo) se administre en los colegios e institutos, pues "en razón de sus efectos y de sus contraindicaciones entra dentro de la categoría de medicamentos susceptibles de suponer un peligro para la salud si son administrados sin vigilancia médica" (www.elpais.com). De esta manera se alteran 
los efectos de la Circular firmada, en diciembre del año 1999, por la ex Ministra de Enseñanza Media, Segoléne Royal, que autorizó a las enfermeras de los institutos a distribuir la llamada pildora del día después entre las menores que la solicitasen de manera razonada".

En sentencia Rol No 1250 del catorce de mayo de 2009, en la que el Tribunal Constitucional asume que la prohibición de la reformatio in peius es parte del derecho al debido proceso contenido en el artículo 19 No 3 de la Constitución, posición que también ha asumido el Tribunal Constitucional español, el cual precisa "resulta constitucionalmente exigible en la medida que su desconocimiento comporta indefensión y puede contravenir la necesaria congruencia que en el recurso ha de existir entre la pretensión impugnatoria y el correspondiente fallo de la sentencia" (sentencias 8/1999, 120/1989 y 120/1995).

En sentencia Rol No 1345 del veinticinco de mayo de 2009, un ministro previniente:

"2. Que dichos reparos de juridicidad al denominado 'solve et repete' también los ha señalado la jurisprudencia emanada de diversos tribunales tanto en Europa como en América, pudiendo citarse el caso de la Corte Constitucional italiana (31 de marzo de 1961) y la judicatura española (26 de noviembre de 1985). En el mismo sentido, se ha encargado de afirmarlo la doctrina autorizada, tanto en nuestro país como en el extranjero".

En sentencia Rol No 1365 de ocho de abril de 2010, el Tribunal Constitucional utiliza la jurisprudencia y legislación comparada para apoyar su consideración jurídica sobre la legitimidad constitucional del establecimiento de los registros de $\mathrm{ADN}$ respecto de delincuentes en el ordenamiento jurídico chileno.

"17. (...) Como ha señalado una sentencia del Tribunal Constitucional alemán, "la investigación del ámbito no codificante de la molécula de ADN tiene por objeto sólo la estructura formal de las secuencias de bases correspondientes a esas moléculas de $A D N$, las cuales no contienen información acerca de las caracteristicas hereditarias del individuo (...). Conforme al estado actual del conocimiento cientifico no es evidente que mediante este tipo de investigaciones queden al descubierto las caracteristicas de la personalidad". (2 BvR 1511/96, de 2 de agosto de 1996). En una sentencia posterior, dicha Magistratura ha agregado que "es decisivo (para estimar que no se ha afectado el núcleo de la personalidad) (...) que no sea posible obtener, a través de la determinación del modelo de identificación del $A D N$, información o conclusiones de situaciones relevantes de la personalidad, como predisposiciones hereditarias, propiedades del carácter o enfermedades de los afectados, que permita crear un perfil de personalidad". (2 BvR 1741/99, de 14 de diciembre de 2000); 
"18. Que tanto el análisis de la doctrina especializada como del derecho comparado, en lo que atinge a los registros de ADN, permite corroborar que, efectivamente, las tomas de muestras biológicas sobre la base del ácido desoxirribonucleico pueden llegar a limitar o restringir derechos fundamentales como los mencionados en el considerando que precede.

"19. Que, desde el punto de vista del derecho comparado, es posible observar que ya son numerosos los paises que cuentan con Registros de ADN (Inglaterra, Irlanda, Escocia, Holanda, Austria, Alemania, Eslovenia, Noruega, Finlandia, Dinamarca, Suiza, Suecia, Croacia, Bélgica, Francia, República Checa, Estonia, Lituania, Eslovaquia y Hungría, tan sólo en Europa), en los cuales suelen utilizarse tres variables que justifican la utilidad del archivo en forma compatible con el respeto de los derechos constitucionales involucrados: a) la gravedad delictual; b) que sean delitos con un alto nivel de reincidencia, y c) la posibilidad de que en la comisión de ese delito se dejen vestigios biológicos, como ocurre con los delitos sexuales (Guillén Vázquez, Margarita. Ob. cit.).

El Consejo de Europa ${ }_{2}$ por su parte, en la Recomendación No R (92) 1, adoptada por el Comité de Ministros, el 10 de febrero de 1992, ha establecido una serie de parámetros para el uso de análisis de ácido desoxirribonucleico (ADN) en el marco de los sistemas de justicia penal, teniendo en cuenta que la introducción y el uso de estas técnicas no puede contravenir principios fundamentales como la dignidad inherente de la persona, el respeto por el cuerpo humano, los derechos de la defensa y el principio de proporcionalidad en la realización de la justicia penal.

En sentencia Rol No 1419-09 de nueve de noviembre de 2010, el Tribunal Constitucional ilustra su análisis sobre eventuales indemnizaciones patrimoniales por vulneración del derecho a la honra y la restricción que ello implicaría a la libertad de expresión, con disposiciones de la Constitución española y alemana que son expresión de una información comparativa irrelevante para el fondo del asunto a ser considerado en la sentencia del Tribunal Constitucional, señalando en su considerando $1^{\circ}$

"Que la Constitución española señala en su artículo 18.1: 'Se garantiza el derecho al honor, a la intimidad personal y familiar y a la propia imagen'. Se trata de 'tres derechos fundamentales que son consecuencia del reconocimiento de la dignidad de la persona humana, integrándose, por su naturaleza, dentro de los denominados derechos de la personalidad'; además, 'se conciben como irrenunciables, inalienables e imprescriptibles, siendo nula la renuncia a los mismos' (José Fernando Merino Merchán y otros: Lecciones de Derecho Constitucional, Tecnos, Madrid, 1995, p. 230). Por su parte, la Ley Fundamental alemana incluye la protección del honor dentro del derecho a la personalidad, establecido en el artículo 2.1, pero se refiere expresamente en el artículo 5.2 al derecho al honor personal como limitación del derecho de expresión". 


\section{CONCLUSIONES}

La recepción de jurisprudencias de tribunales extranjeros o de tribunales internacionales no vinculantes para el Estado de Chile, como es posible de constatar de acuerdo con las fuentes del derecho vigente, no reposa en ningún principio jurídico, constituyendo una práctica corriente de nuestro Tribunal Constitucional y en general de los tribunales constitucionales latinoamericanos y europeos, cuando consideran resoluciones de otras cortes o jurisdicciones constitucionales, no encontrándose obligados a realizar dicho diálogo o comunicación interjurisdiccional.

Puede sostenerse del análisis de la jurisprudencia y citas constitucionales extranjeras o de tribunales internacionales no vinculados jurídicamente con el Estado chileno que realiza nuestro Tribunal Constitucional, posibilita a los jueces constitucionales ampliar o expandir la forma de reflexionar acerca de los argumentos posibles; examinar las diversas tendencias jurídicas; considerar los enfoques teóricos y las estructuras disponibles para la toma de decisiones en casos concretos; utilizar elementos de razonamiento, métodos y enfoques para interpretar la Constitución con una mayor riqueza argumental, en una perspectiva que asume una interpretación evolutiva o dinámica, acorde con la evolución jurídica y los contextos de cada sociedad, dentro de su ámbito de discrecionalidad; utilizar elementos de una dogmática jurídica más amplia y flexible.

El uso adecuado del derecho comparado y la información comparativa es una herramienta útil para las jurisdicciones constitucionales y debe ser alentada cuando es utilizada con método, con rigor, pero no cuando se utiliza simplemente en forma discrecional y descontextuada para apoyar las propias tesis concretando "cherrypicking". Elevar la mirada más allá de la "aldea local" hacia la sociedad global del presente es la práctica de muchos tribunales europeos y latinoamericanos, de derecho continental o de "common law"20, que el Tribunal Constitucional chileno comienza a explorar.

Puede señalarse como otro elemento que se desprende del análisis de las sentencias efectuado, ya sea de las sentencias mismas, como los votos concurrentes o disidentes, que, por regla general, no se dan razones del porqué se ha elegido citar determinados artículos de ciertas constituciones europeas o latinoamericanas y no de otros estados o del porqué se utiliza jurisprudencia en las materias específicas de unos y no de otros tribunales constitucionales o

20 Ver, BARAK, Aharon. (2006). 
cortes supremas; lo que en términos técnicos juríodicos en derecho comparado se denomina ("cherrypicking"), aquí se hace necesario mayor rigor metodológico. Por regla general, en el periodo analizado de la jurisprudencia del Tribunal Constitucional, no hay un análisis sistemático del punto objeto de decisión jurisdiccional en el derecho comparado regional o de países que comparten la misma cultura jurídica; no hay un análisis del contexto en que la disposición constitucional citada extranjera se ubica, las razones de su establecimiento, los valores y principios en que se sustenta, su ubicación en la sistemática constitucional respectiva, la evolución de su interpretación jurisdiccional, por lo que el uso de disposiciones constitucionales extranjeras aisladas puede implicar una grave distorsión de su sentido y alcance correcto en su ordenamiento jurídico de origen y en su interpretación y aplicación. Esto lleva a que deba utilizarse con extrema precaución y prudencia las citas de textos constitucionales ubicándolas en su respectivo contexto jurídico y teniendo presente la interpretación que de ella realizan los órganos competentes para ello.

En este contexto reseñado se justifica que Carozza señale que es preferible emplear el concepto de "comparación interestatal", más que referirse al "método comparativo" o de "análisis comparativo", ya que en las decisiones en que la Corte utiliza la comparación, hay poco análisis y menos método ${ }^{21}$.

Un esbozo de explicación del uso preferencial con poco rigor metodológico de las disposiciones constitucionales extranjeras o de la jurisprudencia de jurisdicciones extranjeras o internacionales no vinculantes jurídicamente para nuestro ordenamiento jurídico, es que los ministros del Tribunal y sus asistentes utilizan a menudo textos académicos de consulta en que se encuentra procesada y ordenada por temas determinada jurisprudencia de algunos tribunales extranjeros o porque se utiliza bibliografía académica en que se encuentra sistematizada la jurisprudencia de ciertos tribunales o cortes constitucionales específicos (de Alemania, España, Francia o Italia en Europa o de Argentina, Colombia, Costa Rica, Perú o México) o de tribunales insternacionales regionales (Corte Europea de Derechos Humanos).

Otro elemento condicionante de la selección de los materiales jurisprudenciales es la consideración de prestigio que tiene para quienes utilizan dicha jurisprudencia el respectivo órgano jurisdiccional de donde emana la sentencia o línea jurisprudencial respectiva. Asimismo, debe tenerse presente la importancia

${ }^{21}$ Carozza, P.G. (1998). pp. 1218-1219. 
de las influencias culturales procedentes de Alemania, España, Francia e Italia en la formación de nuestras escuelas de derecho, a través de las obras originales y traducidas de autores de dichas nacionalidades, los cuales gozan de prestigio en Chile. Por otra parte, la selección se explica también, parcialmente, por la formación jurídica de pre y postgrado recibida por algunos de los magistrados respectivos y los contactos que ellos tienen con magistrados de otros tribunales constitucionales o el manejo de uno u otro idioma en que opera la respectiva jurisdicción constitucional.

El análisis efectuado muestra una insuficiencia estructural institucional de nuestro Tribunal Constitucional, el cual, a diferencia de otros tribunales dotados de mayores recursos y personal letrado, carece de un área o departamento de estudios, análisis y referenciamiento, con una adecuada dotación de personal, el que debiera estar integrado por letrados con suficiente experiencia, formación y conocimiento de idiomas; como, por otra parte, el Tribunal Constitucional carece también de un área importante para un tribunal de tal naturaleza, que pueda encargarse del análisis de congruencia y estilo en la emisión de sentencias, lo que no puede quedar entregado a la buena voluntas de uno u otro Ministro del Tribunal, los cuales son elementos determinantes para elaborar sentencias de mayor calidad jurídica, lo que se encuentra en una parte importante de tribunales constitucionales y cortes europeas (las de Alemania, Italia, Francia o España, para sólo señalar las más conocidas a nivel nacional, o el Tribunal Europeo de Derechos Humanos en el plano regional europeo) y algunas jurisdicciones latinoamericanas como son la Corte Suprema argentina, la Corte Constitucional colombiana, la Suprema Corte Federal de México y la Corte Suprema Norteamericana, para señalar sólo algunos ejemplos.

La consideración de las citas al Tribunal Europeo de Derechos Humanos se explican por ser un tribunal continental europeo con una tradición de más de medio siglo, donde su jurisprudencia es referencia obligada para las jurisdicciones nacionales europeas y donde existen una diversidad de obras en español, inglés, francés, italiano o alemán que han sistematizado su jurisprudencia por temas, la que se encuentra al alcance de cualquier interesado en la materia, además de que ella se encuentra en su página web con un buscador bastante amistoso y manejable.

La riqueza doctrinal que emana de una abundante jurisprudencia del Tribunal Europeo de Derechos Humanos sobre muchos ámbitos de derechos vinculantes para el gran número de países que integran el Consejo de Europa, 47 países, mucho más amplio que los países que forman parte de la Unión Europea, no 
puede compararse con la jurisprudencia de la Corte Interamericana de Derechos Humanos, que ha comenzado a operar décadas después, en materia de derechos más básicos producto de las experiencias de regímenes autocráticos militares que se vivieron (vida, integridad personal, libertad individual, desapariciones forzadas, derecho a la jurisdicción y debido proceso, libertad de información), que han ocupado y consumido sus principales energías durante parte importante del último tercio del siglo XX y primera década del siglo XXI. Asimismo, la mayor riqueza jurisprudencial del Tribunal Europeo de Derechos Humanos se debe también a la incomparable mayor cantidad de casos de los que conoce el Tribunal Europeo de Derechos Humanos de las diversas culturas y concepciones del derecho vigente en los Estados partes de Europa. En esta última perspectiva, cabe señalar que en Estrasburgo se dictan 1800 sentencias anualmente, frente a alrededor de 30 sentencias que dictan anualmente en San José.

Las materias en que se utiliza la jurisprudencia de jurisdicciones constitucionales extranjeras es variada como hemos podido determinar en este artículo, la que considera dimensiones de atributos y garantías de derechos fundamentales en su mayor parte, donde también aparecen menciones significativas a la jurisprudencia del Tribunal Europeo de Derechos Humanos. En una menor medida, la referencia está referida a instituciones de derecho constitucional orgánico.

La cita de disposiciones constitucionales y de jurisprudencia constitucional extranjera no siempre es para asumirla, sino como se evidencia en algunas sentencias del Tribunal Constitucional es también para precisar la existencia de diversos modelos institucionales e incluso para contrastar enfoques normativos diferentes.

Puede apreciarse una reducción de las citas a jurisprudencia de jurisdicciones constitucionales extranjeras y del Tribunal Europeo de Derechos Humanos en el año 2011, en contraste con el resto del periodo analizado, sin perjuicio de lo cual, las citas efectuadas el último año investigado son más precisas y tienden a integrar principios de interpretación o enfoques metodológicos que son relevantes en la ratio decidendi de la sentencia del Tribunal Constitucional en cada caso.

La práctica a través de la cual se desarrolla en la actualidad un diálogo o muchas veces monólogo judicial transnacional, en todo caso, una comunicación interjurisdiccional, contribuye a la formación de un consenso internacional sobre ciertas materias que cada vez adquiere más peso. Con ello gana fuerza la idea de un derecho constitucional abierto en el que los jueces constitucionales interactúen para desarrollar, de una mejor manera, y con mayor riqueza metodológica e interpretativa sus funciones en sus respectivos sistemas constitucionales. A ello 
contribuye la participación de ministros de nuestro Tribunal Constitucional en los encuentros de jurisdicciones constitucionales latinoamericanas y la Corte Interamericana de derechos humanos apoyada por el Programa Estado de Derecho para Latinoamérica de la Fundación Konrad Adenauer, la participación en el club de Venezia, entre otros.

Cabe señalar que la necesidad de abordar en una perspectiva seria el análisis de derecho comparado en materia constitucional, lleva consigo la necesidad de reflexionar y optar entre los enfoques funcionalistas para los cuales los problemas institucionales son los mismos y tiene por objeto comparar las soluciones que los diversos ordenamientos han encontrado a los problemas que enfrentan, los cuales son esencialmente comunes para todos los Estados, estableciendo similitudes en altos grados de abstracción, con descuido de las dimensiones culturales, sociales, e histórico-contextuales del marco analítico; y los enfoques expresivistas que ponen su énfasis en la comprensión de las instituciones y normas jurídicas en su contexto cultural, social, político e histórico que deben ser particularmente atendidos en el proceso comparativo normativo e institucional. Asumir uno u otro enfoque genera resultados distintos en la comparación y de ello los jueces constitucionales deben tener suficiente conciencia, ya que el método condiciona el resultado del análisis jurídico. Del contenido de las sentencias de nuestro Tribunal Constitucional puede inferirse que el análisis no ha sido efectuado y que el enfoque hasta ahora ha sido más funcionalista y descontextualizado de sus particularidades normativas, estructurales, contextuales y ambientales.

Finalmente, es necesario tener presente, el dato no menor de que el estudio de la ciencia del derecho comparado ha tenido muy escasa recepción dentro de los planes de estudio de las escuelas y facultades de derecho en nuestro país, reservándose, por lo general, solamente para programas de post grado de reciente desarrollo.

\section{BiBLIOGRAFÍA}

BaraK, Aharon. (2006): The Judge in a Democracy. (Princeton and Oxford. Princeton University Press), 332 pp.

BARAK, Aharon. (2005). Purposive Interpretation in law (Princeton and Oxford: Princeton University Press), $454 \mathrm{pp}$.

BARAK, Aharon. (2009): "La comparazione nell diritto púbblico", en Markensis, Basil y Fedtke, Jörg (2009) Giudice e diritto straniero. La pratica del diritto comparato. (Bologna, Ed Il Mulino), pp. 389-396. 
Brito Melgarejo, Rodrigo. (2010): "El uso de sentencias extranjeras en los Tribunales Constitucionales. Un análisis comparativo". Revista In Dret 2. Revista para el análisis del derecho. Barcelona. 22 pp. www.indret.com consultada en 9 de enero de 2012. http://www.indret.com/pdf/720_es.pdf.

Carozza, P.G. (1998): "Uses and Misures of Comparative Law in International Human Rights: Some Reflections on the jurisprudence of the European Court of Human Rights". Notre Dame Law Review No 73, pp. 1218-1219.

Carpentier, Elice. (2009). "La utilización de la jurisprudencia constitucional extranjera por el Consejo Constitucional francés”. Estudios Constitucionales, año 7 № 2, pp. 129-142.

Choudry, S. (2006). "Migration As a New Metaphor in Comparative Constitutional Law", in Id. (cur.), The Migration of Constitutional Ideas. Cambridge. Cambridge University Press, pp. 1-35.

De Vergottini, Giuseppe. (2010). Oltre il dialogo tra le corti. (Bologna, Ed Il Mulino), $211 \mathrm{pp}$.

De Vergottini, Giuseppe. (2010). Más allá del diálogo entre tribunales. Comparación y relación entre jurisdicciones. (Pamplona. Cuadernos Civitas Thomson Reuters. Ed Aranzadi), 332 pp.

De Vergottini, G. (2004). Diritto Costituzionale Comparato. 6a edición. (Padova, Cedam), 584 pp.

Markesinis, Basil; FedTKe, Jörg. (2009). Giudici e diritto straniero. La pratica del diritto comparato. Il Mulino, Bologna, 489 pp.

García Roca, Javier; Nogueira Alcalá, Humberto y Bustos, Rafael. (2012). La comunicación entre ambos sistemas (sistemas regionales americano y europeo de protección colectiva de los derechos humanos) y las características del diálogo. Ed. Civitas Thomson Reuters, Madrid, pp. 65- 135.

JACKSON, Vicky. (2010). Constitutional Engagement in a Transnational Era. (OxfordNew York. Oxford University Press), 519 pp.

Legrand, Pierre and MundaY, Roderick (eds.) (2003): Comparative Legal Studies: Traditions and Transitions. (New York, Cambridge University Press).

LollinI, Andrea. (2009). "Confronting Comparative Methods: Approaches to Using Extra-Systemic Parameters by the Canadian Supreme Court and the South African Constitutional Court", in A.S. Muller, M.A. Loth, Highest Courts and Internationalisation of Law, The Hague. Hague Academic Press), pp. 165-182. 
Markesinis, Basil y FedtKe, Jörg. (2009). Giudici e diritto straniero. La pratica del diritto comparato, (Bolonia, Il Mulino), $489 \mathrm{pp}$.

Nogueira Alcalá, Humberto. (2011). "El uso de las comunicaciones transjudiciales por parte de las jurisdicciones constitucionales en el derecho comparado y chileno". Estudios Constitucionales, Año 9, No 2, 2011, pp. 1 -76.

Nogueira Alcalá, Humberto. (2012). "El uso del derecho convencional internacional de los derechos humanos en la jurisprudencia del Tribunal Constitucional chileno en el periodo 2006-2010", Revista Chilena de Derecho, vol. 39 No 1, pp. 149-187.

Nogueira Alcalá, Humberto. (2011). "El uso del Derecho extranjero y del Derecho internacional por parte del Tribunal Constitucional chileno durante el periodo 2006-2007". Revista de Derecho de la Pontificia Universidad Católica de Valparaíso, XXXVII, 2o Semestre de 2011, pp. 275-326.

Pegoraro, Lucio. (2007) "La utilización del Derecho Comparado por parte de las Cortes Constitucionales: un análisis comparado". Revista General de Derecho Público Comparado. Iustel No 1, 2007.

Pegoraro, L. y Rinella. (2002). A. Introducione al Diritto Pubblico Comparato. Metodología di ricerca, (Padova, Cedam), pp. 3-88.

Pegoraro, Lucio. (2001). "El método en el Derecho constitucional: la perspectiva desde el Derecho comparado". Revista de Estudios Políticos, No 112, 2001, pp. 9-26.

Pegoraro, L. y Damiani, P. (1999). "El derecho comparado en la jurisprudencia de los Tribunales Constitucionales". Revista Jurídica de Castilla La Mancha, No 28, pp. 209-236.

Pizzorusso, Alessandro (1998): Sistemi giuridici comparati, 2a ed. (Milán. Giuffrè), $412 \mathrm{pp}$.

Ponthoreau, Marie Claire. (2009). "L'argument fondé sur la comparaison dans le raisonnement juridique”, (sous dir.) P. Legrand, Comparer les droits résolument, PUF, 648, pp. 537-560.

Santana Herrera, María Soledad. (2010). "El derecho comparado en la jurisprudencia del Tribunal Constitucional español". Revista de Derecho Constitucional Europea, año 7 No 14, julio-diciembre 2010, pp. 427-447.

Scheppele, Kim Lane. (2003). "Aspirational and Aversive Constitutionalism: The Case for Studying Cross-Constitutional Influence through Negative Models" 1:2 Int'l J. Const. L. (I.CON), pp. 296-324. 
SlaUgTHER, Anne-Marie. (1994). "A tipology of transjudicial communication", 29 University of Richmond Law Review, pp. 99-137.

VON BAR, C. (2004). "Comparative Law of obligations: metodology and epistemology”, en Van Hoecke, M. (Edited by), Epistemology and metodology of Comparative Law, (Oregon, Oxford and Portland. Hart Publishing), pp. 123-135.

Zagrebelsky, Gustavo. (2008): La legge e la sua giustizia. (Bolonia. Il Mulino), $419 \mathrm{pp}$.

ZWEIGERT, Konrad y KÖTZ, Hein (2008): Introducción al derecho comparado. trad. Arturo Aparicio Vásquez, (México D.F. Oxford University Press), 771 pp.

Jurisprudencia Citada

Tribunal Constitucional

Año 2006

Sentencia, Rol No 480, de 27 de julio de 2006.

Sentencia Rol No 546, de 17 de noviembre de 2006.

\section{Año 2007}

Sentencia Rol No 519, de 5 de junio de 2007.

Sentencia Rol No 527, de 31 de enero de 2007.

Sentencia Rol No 549, de treinta de marzo de 2007.

Sentencia Rol No 576, de veinticuatro de abril de 2007.

Sentencia Rol No 616, de seis de septiembre de 2007.

Sentencia Rol No 664, de 30 de mayo de 2007.

Sentencia Rol No 718, de 26 de noviembre de 2007.

Sentencia Rol No 759, de 26 de noviembre de 2007.

Sentencia Rol No 773, de 26 de noviembre de 2007.

Sentencia Rol No 783, de 14 de mayo de 2007.

Sentencia Rol No 786, de 13 de junio de 2007.

Sentencia Rol No 790, de 11 de diciembre de 2007.

\section{Año 2008}

Sentencia Rol No 740, de 18 de abril de 2008.

Sentencia Rol No 755, 31 de marzo de 2008, 
Sentencia Rol No 974, de 31 de enero de 2008. Sentencia Rol No 878, de 24 de enero de 2008. Sentencia Rol No 880, de 24 de enero de 2008. Sentencia Rol No 978, de 24 de enero de 2008. Sentencia Rol No 821, de $1^{\circ}$ de abril de 2008. Sentencia Rol No 968, de 10 de julio de 2008. Sentencia Rol No 986, de 30 de enero de 2008. Sentencia Rol No 1029, de 10 de julio de 2008. Sentencia Rol No 1170, de 26 de agosto de 2008. Sentencia Rol No 1216, de 30 de octubre de 2008. Sentencia Rol No 1133, de 18 de noviembre de 2008.

Sentencia Rol No 1138, de 11 de septiembre de 2008.

Sentencia Rol No 1056, de 18 de noviembre de 2008.

Sentencia Rol No 1065, de 18 de diciembre de 2008.

Sentencia Rol No 1170, de 26 de agosto de 2008.

Sentencia Rol No 1216, de 30 de octubre de 2008.

\section{Año 2009}

Sentencia Rol No 1173, de 17 abril de 2009.

Sentencia Rol No 1204, de 25 de mayo de 2009.

Sentencia Rol No 1140, de 14 de enero de 2009.

Sentencia Rol No 1247, de 14 de julio de 2009.

Sentencia Rol No 1250, de 14 de mayo de 2009.

Sentencia Rol No 1254, de 29 de julio de 2009.

Sentencia Rol No 1288 de 25 de agosto de 2009.

Sentencia Rol No 1288, de 25 de agosto de 2009.

Sentencia Rol No 1340, de 29 de septiembre de 2009.

Sentencia Rol No 1345, de 25 de mayo de 2009.

Sentencia Rol No 1295, de 6 de octubre de 2009.

Sentencia Rol No 1340, de 4 de marzo de 2009.

Sentencia Rol No 1345, de 25 de mayo de 2009.

Sentencia Rol No 1361, de 13 de mayo de 2009. 


\section{Año 2010}

Sentencia Rol No 557-2006, de 2 de junio de 2010.

Sentencia Rol No 567, de 3 de junio de 2010.

Sentencia Rol No 1273, de 20 de abril de 2010.

Sentencia Rol No 1348, de 27 de abril de 2010.

Sentencia Rol No 1365, de 8 de abril de 2010.

Sentencia Rol No 1399, de 4 de noviembre de 2010.

Sentencia Rol No 1413-09, de 16 de noviembre de 2010.

Sentencia Rol No 1414, de 14 de septiembre de 2010.

Sentencia Rol No 1419, de 9 de noviembre de 2010.

Sentencia Rol No 1445, de 29 de enero de 2010.

Sentencia Rol No 1535, de 28 de enero de 2010.

Sentencia Rol No 1545, de 28 de enero de 2010.

Sentencia Rol No 1469, de 4 de noviembre de 2010.

Sentencia Rol No 1576, de 16 de diciembre de 2010.

Sentencia Rol No 1588, de 14 de enero de 2010.

Sentencia Rol No 1710, de 6 de agosto de 2010.

\section{Año 2011}

Sentencia Rol No 1537-09, de $1^{\circ}$ de septiembre de 2011.

Sentencia Rol No 1656-10, de 10 de septiembre de 2011.

Sentencia Rol No 1683-10, de 4 de enero de 2011.

Sentencia Rol No 1881-10, de 3 de noviembre de 2011. 